\title{
A LONGITUDINAL EXAMINATION OF THE PARENT-CHILD DISTRESS RELATIONSHIP IN CHILDREN WITH JUVENILE RHEUMATIC DISEASE
}

\author{
By \\ JAMIE L. RYAN \\ Master of Arts in Clinical Psychology \\ University of Northern Iowa \\ Cedar Falls, Iowa \\ 2008
}

Submitted to the Faculty of the

Graduate College of the

Oklahoma State University

in partial fulfillment of

the requirements for

the Degree of

MASTER OF SCIENCE

July, 2010 


\section{A LONGITUDINAL EXAMINATION OF THE PARENT-CHILD DISTRESS RELATIONSHIP IN CHILDREN WITH JUVENILE RHEUMATIC DISEASE}

Thesis Approved:

\begin{tabular}{l} 
Larry L. Mullins, Ph.D. \\
\hline Thesis Adviser \\
John M. Chaney, Ph.D. \\
Melanie C. Page, Ph.D. \\
A. Gordon Emslie, Ph.D.
\end{tabular}




\section{ACKNOWLEDGMENTS}

I would like to thank my major advisor, Dr. Larry Mullins, for his support and encouragement on this project. I would also like to express my appreciation for my other committee members, Dr. John Chaney and Dr. Melanie Page. Dr. Chaney’s expertise in this area provided me with a great opportunity to learn about a different method of statistical analysis, and Dr. Page's suggestions and contributions were helpful and thought provoking. Additionally, I would like to thank Dr. James Jarvis who generously provided me with the access to his pediatric rheumatology clinic and was always willing to offer his medical expertise. I'd also like to thank my lab members for their dedication and assistance on this project. Finally, I wish to thank my loving family. Although we are separated my hundreds of miles, their words of encouragement and support throughout this project have been felt on a daily basis. 
TABLE OF CONTENTS

Chapter $\quad$ Page

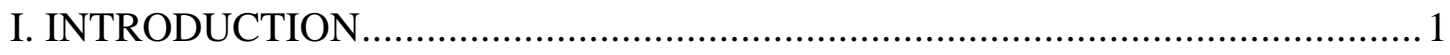

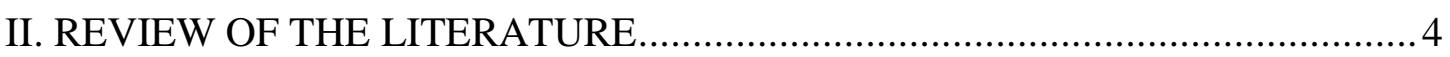

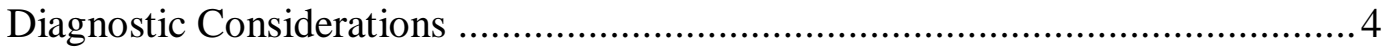

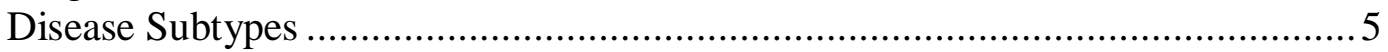

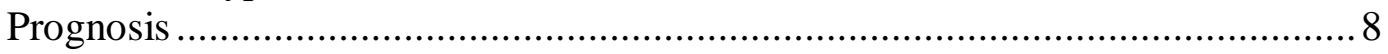

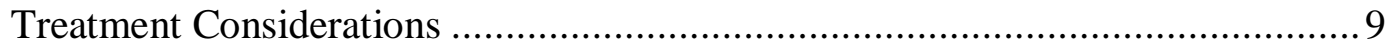

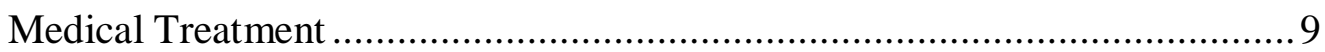

Psychological Treatment ....................................................................... 12

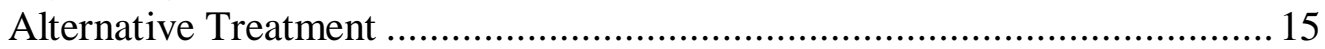

Psychological Comorbidity in JRDs .............................................................. 17

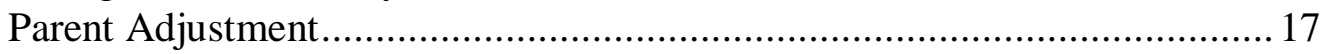

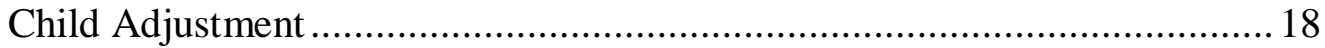

Transactional Stress and Coping Model .......................................................2 21

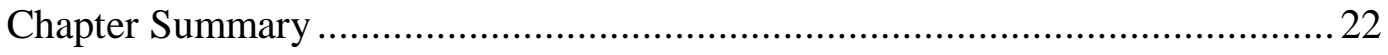

III. PRESENT STUDY

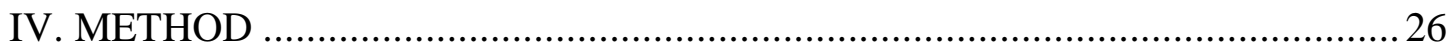

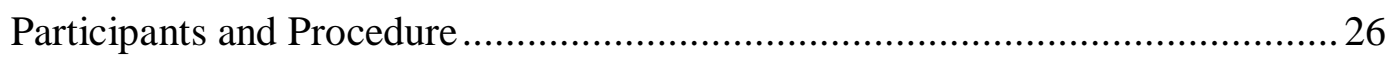

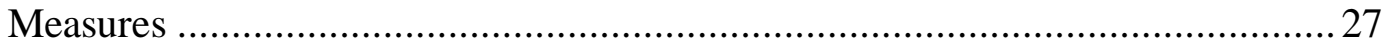

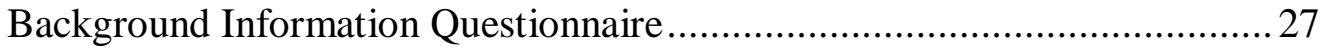

Physician-Rated Functional Disability.....................................................2

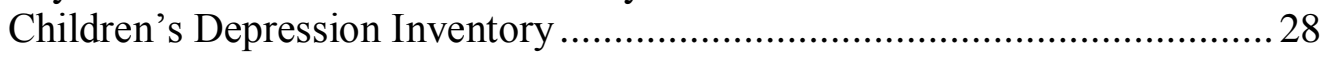

Juvenile Arthritis Functional Assessment Report-Child............................... 28

Brief Symptom Inventory ........................................................................2 29

Juvenile Arthritis Functional Assessment Report-Parent..............................2 29

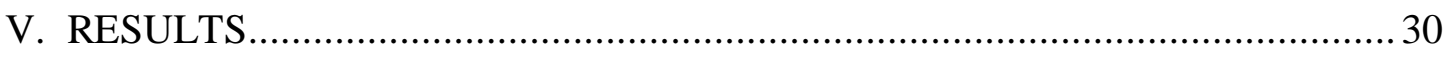

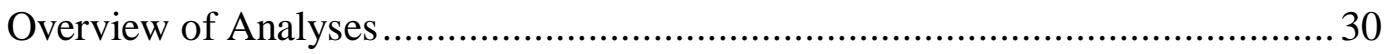

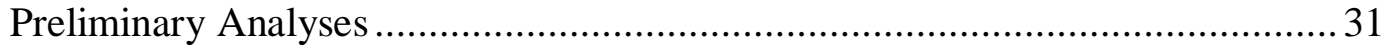

Cross-lagged Panel Analysis ......................................................................... 32

Cross-lagged Correlation Comparisons ………......................................... 33 


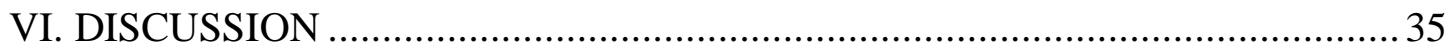

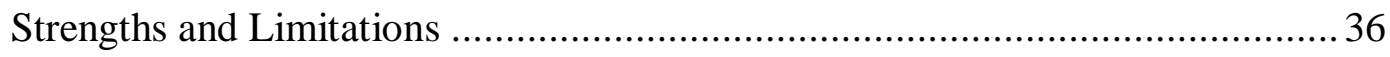

Implications and Recommendations for Future Research ....................................39

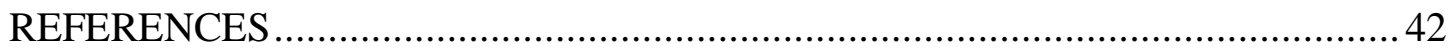

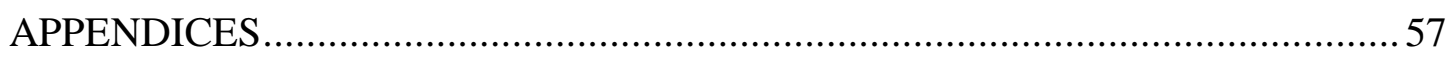

APPENDIX A - BACKGROUND INFORMATION QUESTIONNAIRE..........57

APPENDIX B - PROVIDER QUESTIONNAIRE........................................... 60

APPENDIX C - CHILDREN'S DEPRESSION INVENTORY .........................63

APPENDIX D - JUVENILE ARTHRITIS FUNCTIONAL ASSESSMENT

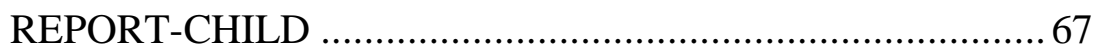

APPENDIX E - BRIEF SYMPTOM INVENTORY ………….........................69

APPENDIX F - JUVENILE ARTHRITIS FUNCTIONAL ASSESSMENT

REPORT-PARENT ......................................................... 73

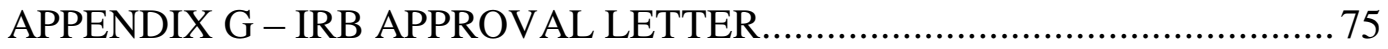




\section{LIST OF TABLES}

Table

Page

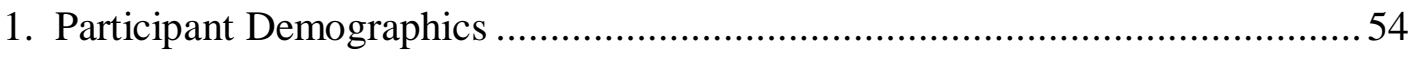

2. Correlations Between Parent and Child Distress............................................ 55 


\section{LIST OF FIGURES}

Figure $\quad$ Page

1. Cross-Lagged Panel Design and Partial Correlations .......................................56 


\section{CHAPTER I}

\section{INTRODUCTION}

Arthritis is generally considered a disease of older adults, but approximately 300,000 children and adolescents in the United States currently suffer from some form of arthritis or rheumatic disease (Lehman, 2008). Juvenile rheumatic diseases (JRDs) represent a heterogeneous group of chronic childhood disorders, such as juvenile rheumatoid arthritis, systemic lupus erythematosus, juvenile dermatomyositis, and juvenile spondyloarthropathies. These diseases are characterized by joint pain, swelling, and stiffness, fluctuating in intensity, and often resulting in restricted mobility and activity (Cassidy \& Petty, 2001).

In addition to the pain and disability associated with JRDs, children and adolescents are impacted across several domains, including emotional and psychological functioning. In general, studies indicate that children and adolescents diagnosed with a JRD are at increased risk for further psycho-social adjustment problems, including depression, anxiety, and social withdrawal (Chaney et al., 1996; Reiter-Purtill, Gerhardt, Vannatta, Passo, \& Noll, 2003; Vandvik, 1990). Similarly, parents of children with a JRD must also adjust to their child's illness in addition to dealing with the financial burden associated with treatment. As a result, they are impacted in ways quite similar to their children, such as increased feelings of guilt, anxiety, anger, hopelessness, and isolation (Barlow, Harrison, \& Shaw, 1998). 
In addition to the compelling body of evidence demonstrating that both children with JRDs and their parents experience an increased vulnerability to psychological distress, researchers have developed multivariate conceptual models that characterize parent and child adjustment to chronic illness as a transactional process. One such model is Thompson and Gustafson's transactional stress and coping model, which proposes that parent and child (mal)adjustment are not the direct outcome of any one factor, but rather a complex function of the interplay between child and parent variables, as well as illness (e.g., illness type, duration, and severity) and demographic parameters (e.g., child age, gender, and SES) (Thompson, Gil, Burbach, Keith, \& Kinney, 1993). As such, both the individual and reciprocal function of child and parent distress are integral components of transactional adjustment models in pediatric chronic illness. Across a variety of pediatric chronic illnesses (e.g., JRD, diabetes, asthma, sickle cell disease), cross-sectional and longitudinal studies have consistently demonstrated the reciprocal nature of the parent distress-child distress relationship (e.g., Chaney et al., 1997; Hocking \& Lochman, 2005; Mullins \& Chaney, 2001; Thompson, Gustafson, Gil, Kinney, \& Spock, 1999; Thompson, Gustafson, George, \& Spock, 1994; Wagner, et al., 2003; White et al., 2005). Although empirical investigations have reliably established the transactional nature of parent-child adjustment outcomes, the predominant direction of this relationship is not known. In other words, extant studies in the child chronic illness literature consistently reveal a reciprocal link between parent and child distress; however, no 
known study exists that indicates whether parent and child distress share equal valence in this transactional process, or if one is causally predominant. Delineating the nature of the parent-child distress relationship could yield a variety of conceptual, empirical, and research implications.

Therefore, the current study is designed as an initial step in addressing this gap in the literature by examining the longitudinal nature of the association between parent and child distress in a sample of children and adolescents diagnosed with a JRD and their parents. Specifically, using a cross-lagged panel correlation design (Kenny, 1975), the present study aims to explore the temporal precedence of parent distress and child distress in the parent-child distress relationship over the course of one year. 


\section{CHAPTER II}

\section{REVIEW OF THE LITERATURE}

\section{Diagnostic Considerations}

Juvenile Rheumatic Diseases (JRD) are a series of autoimmune disorders characterized by a similar presentation of symptoms, including joint pain and swelling, connective tissue inflammation, chronic pain or tenderness in the joint(s), and possible limited movement in the affected joint(s) (Vandvik \& Hoyeraal, 1993). Correctly diagnosing juvenile rheumatoid arthritis (JRA) and other rheumatic diseases is often a challenge, as many symptoms are similar among the different diseases yet vary across individuals and in terms of disease severity. To make an accurate diagnosis, a physician may need to conduct the following: physical examination, laboratory testing (e.g., antinuclear antibody, complement, hematocrit), x-rays and other imaging tests (e.g., MRI), and subjective pain measurement. Despite a potentially lengthy and complex differential diagnostic process, one diagnosis may later fit better with another JRD once specific disease markers are present (Cassidy \& Petty, 2001). Especially true for JRA, $22 \%$ of diagnosed children receive a "replacement diagnosis" within 10 years (Flato, Aasland, Vinje, \& Forre, 1998). Consequently, a diagnostic process that is typically designed to provide clarity and reassurance to the family is often times clouded by the unpredictable and unstable nature of the disease, further exacerbating the feelings and attitudes toward the illness. 


\section{Disease Subtypes}

As previously stated, JRDs consist of a series of autoimmune disorders including juvenile rheumatoid arthritis (JRA), systemic lupus erthematosus (SLE), juvenile dermatomyositis (JDMA), and juvenile spondylarthropathies. Although they share several features, there are some distinctive characteristics, such as the number of affected joints and the degree of restricted movement.

Juvenile rheumatoid arthritis (JRA) is the most commonly diagnosed JRD, with key features including swollen, stiff, and painful joints, inflammation, warmth and redness in the joint(s), pain, and fatigue (Lehman, 2004). Of note, some atrophy of the muscles surrounding the affected joint(s) is common, and can also affect bone development in a growing child (Cassidy \& Petty, 2001). According to the criteria of the American College of Rheumatology, JRA is the proper diagnosis for any child with the onset of arthritis before 16 years of age if the arthritis lasts at least six weeks in more than one joint or three months in a single joint (Lehman, 2004). Thus, every child with chronic arthritis has JRA; however, not every child with arthritis has the same condition. In addition, JRA affects girls twice as often as boys and is more common in Caucasian children than in either African American or Asian American children (Lovell, 1997).

The disease can be classified into three categories depending on the number of and which joints are involved, the symptoms present and their duration, and the presence or absence of specific antibodies. JRA is categorized into one the following subtypes: pauciarticular, polyarticular, or systemic.

Pauciarticular JRA is a common form involving four or less joints and typically affects larger joints (e.g., knee, shoulder, hip). Occurring in approximately $50 \%$ of 
children with JRA, this type of disease most often affects girls younger than eight years (Lovell, 1997). Although arthritis is typically the only disease manifestation, children with this subtype have a $20-30 \%$ chance of developing inflammatory eye problems, and children younger than eight years are at greater risk of developing an adult form of arthritis (Kotaniemi, Kaipiainen-Seppänen, Savolainen, \& Karma, 1999).

The next most common subtype is polyarticular JRA, affecting one-third to onehalf of children with JRA. Involving five or more joints, polyarticular JRA is more serious and tends to affect the small joints (e.g., hands and feet) on both sides of the body (i.e., symmetrical arthritis). Common symptoms include a positive blood test for rheumatoid factor (RF), bumps on parts of the body (e.g., elbow) that receive a lot of pressure from chairs, shoes, or other objects, and low red blood cell count (i.e., anemia) (Cassidy \& Petty, 2001). Although onset is not necessarily age-specific, girls are three times more likely than boys to be diagnosed with this subtype (Lehman, 2004). This is a heterogeneous group of diseases. For instance, there are two major peaks in the age of disease onset; between eighteen months and eight years of age and after eleven years of age. Furthermore, some children begin with arthritis in one or two joints, slowly spreading to other joints, while other children rapidly develop arthritis in multiple joints (Lehman, 2004).

Similar to pauciarticular JRA, children with this subtype are at risk for developing chronic eye problems (e.g., uveitis) and should be evaluated by an ophthalmologist on a regular basis. Of similar importance, children with polyarticular JRA may develop permanent damage to some of their joints. For example, arthritis in the jaw may cause 
pain and discomfort in chewing, affecting dental care and eating habits, and ultimately impinging the growth process.

The third and most serious subtype, systemic JRA (also called Still's disease), occurs independent of both age and gender and affects approximately $10 \%$ of children with JRA (Cassidy \& Petty, 2001). This type of JRA is associated with high fevers, a rash, arthritis, and in some children, inflammation of internal organs (e.g., heart, liver, spleen). The following notes need mention for a proper diagnosis: the fever must fall back to normal at least once each day, the rash should have a salmon pink appearance (not like a bruise), and the rheumatoid factor should not be present (Lehman, 2004). If any of the aforementioned factors does not hold true, a diagnosis of systemic JRA is probably wrong. For some children, the fever and rash may disappear after the first few months of the illness, while the joint-related pain may persist for a longer period of time. Long-term problems due to systemic JRA are similar to the other subtypes, with eye problems occurring less frequently (Kotaniemi et al., 1999).

Although the other rheumatoid diseases share the arthritic feature of the aforementioned JRA subtypes, they have distinct characteristics. Systemic lupus erythematosus (SLE), for example, is a disease characterized by periodic episodes of inflammation of the joints, tendons, and other connective tissue. In severe cases, complications may include blood clots, strokes, and kidney and/or heart failure (Lovell, 1997). Unlike JRA, arthritis in children with SLE does not cause joint damage or deformity (Lehman, 1997). SLE symptoms often emerge during early adolescence (10 years and older), with girls accounting for more diagnoses than boys (Cassidy \& Petty, 2001). African Americans, Asian Americans, Latinos, and Native Americans are most 
often affected by SLE as compared to Caucasian Americans. Similar to other rheumatic diseases, SLE is known to have flare-ups and periods of remission, although the severity of kidney involvement in SLE can vastly alter the outcome and survival rate of children with the disease.

Juvenile spondylarthropathies compromise a class of rheumatic diseases distinctly different from other rheumatic illnesses, with juvenile ankylosing spondylitis (JAS) as the most common subtype. Occurring two to three times more often in boys than girls, the onset of JAS typically takes places during late childhood or pre-adolescence (Lehman, 2004). JAS commonly causes pain and inflammation in the joints in the lower part of the body, especially at the site of attachment of muscles, ligaments, and/or tendons to bone. Although prognosis is usually good if detected early (Khan, 1993), severe cases can involve erosion at the joint between the spine and the hip bone and the formation of bony bridges between vertebrae in the spine, fusing the bones and permanently limiting mobility (Cassidy \& Petty, 2001).

Lastly, juvenile dermatomyositis (JDMA) is a disease characterized by muscle damage due to diffuse vasculitis (Cassidy \& Petty, 2001). Symptoms often appear gradually and include fever, a rash around the eyelids and/or knuckles, joint pain and tenderness, and mouth ulcers. JDMA is rare and affects girls from ages four to fourteen more often than boys (Lehman, 2004). Similar to other rheumatic diseases, the cause is unknown although JDMA is usually triggered by a condition (e.g., infection, immunization, injury) that causes immune system activity that does not respond as it should (Feldman, Rider, Reed, \& Pachman, 2008).

Prognosis 
JRDs are unpredictable and unstable, often fluctuating between flare-ups and periods of remission (Lehman, 2004). Approximately $80 \%$ of adolescents with JRA eventually enter remission with minimal functional loss or deformity (Lehman, 2004). Because of further complications and the impact on other body systems, children and adolescents diagnosed with a JRD are more likely to have arthritis as adults and show greater mortality rates than the general population (Cassidy \& Petty, 2001). Fortunately, JRDs are seldom life-threatening, with fatalities mostly occurring among children with SLE due to organ failure (Cassidy \& Petty, 2001).

The key to a positive prognosis is the prevention and correction of potentially damaging affects with proper therapy. As with many other childhood diseases, the majority of children and families who keep their appointments and comply with medications and other interventions will do well as compared to those who regularly miss appointments for extended periods of time and who often refuse advice for more aggressive therapy (Lehman, 2004). Although the outlook is hopeful, there is no way to ultimately predict the outcome for children diagnosed with a JRD, further highlighting the importance of examining factors associated with more positive results.

\section{Treatment Considerations}

\section{$\underline{\text { Medical Treatment }}$}

For all individuals diagnosed with a JRD, the primary goals of any drug therapy are to reduce pain and inflammation of the joint(s) and maximize the ability to perform activities of daily living. In the long-term, goals include the prevention of disease progression and destruction of bone, cartilage, and joints. Often times, the first line of therapy include nonsteroidal anti-inflammatory drugs (NSAIDs). All NSAIDs interfere to 
varying degrees with the cyclooxygenase pathway, which is responsible for the production of important inflammatory mediators (e.g., prostaglandins) (Lehman, 2004). At low doses, NSAIDs help with a variety of problems, ranging from muscle aches to pain and fever, whereas higher prescribed doses help reduce joint inflammation. NSAIDs fall into three general categories: traditional NSAIDs (i.e., COX-1), COX-2 inhibitors, and salicylates.

Traditional NSAIDs compromise the largest subset, with three of them in lowerstrength doses and available without a prescription. Because of the side effects of many traditional NSAIDs, including bleeding and liver and stomach problems, COX-2 inhibitors (e.g., Celebrex, Vioxx) are a class of NSAIDs found to be gentler on the stomach (Lehman, 2004). As with any medication, however, there is a risk of side effects such as cough, cold, upper respiratory tract infection, headache, fever, and nausea. COX2 inhibitors have been found to increase the risk of heart problems in adults, and studies are currently examining similar risks in children (Ilowite, 2002). Once the most common and single most effective anti-inflammatory medication in treating JRA, the use of salicylates (aspirin) has greatly declined due to the risk of Reye's syndrome, a rare but potentially lethal disease that attacks the liver and brain when a person is recovering from a viral illness (Lehman, 2004).

Although only a handful are approved by the U.S. Food and Drug Administration (FDA) for use in JRA (e.g., ibuprofen, naproxen, tolmetin, and choline magnesium trisalicylate), many other NSAIDs are commonly prescribed, including indomethacin and diclofenac (Ilowite, 2002). Because of a lack of consensus on the best NSAID for patients 
with JRA, many medications are chosen on the basis of considerations such as cost, dosing schedule, patient preference, or medication taste.

When NSAIDs alone fail to reduce pain and inflammation, physicians may prescribe additional disease-modifying anti-rheumatic drugs (DMARDs) to slow the progression of JRA. Commonly used DMARDs in the treatment of JRA include methotrexate (Rheumatrex) and sulfasalazine (Azulfidine). DMARDs are typically started early because it may take up to three to four months before effects are noticed (Lehman, 2004). Common side effects include nausea, minor changes in the white blood cell or platelet count, and liver irritation. In more severe cases of polyarticular or systemic arthritis, corticosteroids may be used. Because of adverse side effects, including increased susceptibility to infection, corticosteroids are often used only if the others have failed.

Biologics are a new class of medications that have been shown to provide significant relief to children with JRA by targeting a specific molecule that plays an important role in the inflammatory process (Lehman, 2004). Enbrel, the first widely available biologic, has been found to be effective for most children with polyarticular arthritis, spondyloarthropathies, and some children with systematic arthritis. Enbrel works by interfering with the function of a molecule called tumor necrosis factor alpha (TNF- $\alpha$ ), a messenger molecule that often causes people to feel ill when released in large amounts (Lehman, 2004). Early studies suggest that Enbrel works within hours of the first dose and not only prevents symptoms of the disease, but also allows healing of the bone and joint damage to begin. Common side effects include runny nose, skin reactions, 
and headaches. Further considerations prior to using Enbrel include its high cost and the subcutaneous injections required twice weekly (Lehman, 2004).

Psychological Treatment

While medical treatment of JRA serves its purpose in the maintenance of the disease symptoms, psychological interventions have been shown to be important adjunctive therapies that help patients manage pain, facilitate psychosocial adjustment, and enhance adherence to medication regimens. For example, cognitive behavioral therapy (CBT) for pain management has demonstrated that by improving self-efficacy, patients were more likely to report a reduction in pain and depressive symptoms and take their medication as prescribed (O’Leary, Shoor, Lorig, \& Holman, 1988). Furthermore, CBT for children with JRA has been shown to reduce pain after the introduction of various self-regulatory techniques (Walco, Varni, \& Ilowite, 1992).

In general, traditional CBT for pain management/coping skills training consists of three phases: 1) psychoeducation about the biofeedback model of pain; 2) skills-training (e.g., relaxation training, pleasant activity scheduling, imagery, cognitive restructuring, problem solving, goal setting); and 3) practice and application of skills in real-life situations (Turk, 2002). Specifically, children between the ages of 4.5 and 16.9 years with JRA were seen for eight individual sessions and taught a variety of techniques (e.g., muscle relaxation, meditative breathing). Results indicated a reduction in self-reported pain and increased adaptive functioning that continued at 6- and 12-month follow-up (Turk, 2002).

Because CBT for chronic pain conditions, such as JRDs, are often implemented as part of a larger treatment plan, teaching children several pain management skills is 
commonly utilized. Although not targeting JRDs, Gil and colleagues (2001) found that teaching children diagnosed with sickle cell disease to use calming self-statements (e.g., "be brave, hang in there") and pleasant imagery over the course of two sessions resulted in less negative thinking and lower pain during laboratory conducted pain tasks.

However, the improvements were not maintained over a one-month follow-up period, suggesting a need for a more intensive intervention that lasts longer than two weeks.

Complimentary to CBT for pain management, biofeedback training helps patients increase control over their physiological processes that may contribute to the experience of pain. During training, a clinician educates the patient on physiological responses to stress and pain, often with the use of an electronic device that records physiological signals (e.g., heart rate, blood pressure). The goal is to help the patient gain control over the responses (e.g., muscle tension, anxiety) that can contribute to pain (Dixon, Keefe, Scipio, Perri, \& Abernethy, 2007).

Unlike CBT for pain management, stress management training primarily focuses on managing stress, not pain per se. Similarly, however, stress management training includes skill building, such as deep breathing, meditation, relaxation training, and visual imagery. Although the major goal is the reduction of stress, it is expected that this will translate into better symptom control and pain management (Dixon et al., 2007).

Another more recent treatment option that has received increased attention is operant interventions, focused on modifying the child's overt manifestations of pain (e.g., crying, groaning, and grimacing). Introduction came from speculation that pain behaviors are maintained by positive or negative reinforcement, such as extra time with a parent, visits from friends, or gifts from friends or family. Allen and Shriver (1998) examined 
such reinforcement comparing biofeedback alone and in combination with an operant intervention. Children between the ages of 7- and 18-years with migraine headaches received positive reinforcement for adaptive coping strategies and maintaining daily activities and no reinforcement for inappropriate pain behaviors. Although both groups reported significantly less migraines, children in the operant intervention condition made greater gains and were more likely to be free of migraines at the end of treatment and at three-month follow-up. The groups were not significantly different at one-year follow-up (Allen \& Shriver, 1998).

Lastly, because children with JRA face numerous stressful situations associated with the acute exacerbations of their disease and the long-term functional disability that may follow, the family has been identified as an important source of support in the coping process for a chronically ill child (Varni, Wilcox, \& Hanson, 1988). For instance, Wallander and Varni (1989) demonstrated that chronically ill or handicapped children with high social support showed significantly better psychological adjustment when compared to those with low social support. Several earlier studies have further supported the positive relationship between social support and functioning in adults with JRA (Kaplan \& Delongis, 1983; Nicassio, Brown, Wallston, \& Szydlo, 1985; Weinberger, Hiner, \& Tierney, 1986).

In sum, psychosocial treatment for JRDs is wide-spread with each offering a unique component depending on various disease and environmental factors, such as disease severity or subtype, and the cost, preference, and feasibility of the treatment options. The current study aims to add to the extant literature with the role that cognitive processes (e.g., attitude) play into treatment recommendations. 


\section{Alternative Treatment}

Because potential side effects and long-term damage are a concern to most parents of children with JRA, many inquire about alternatives, including vitamins and supplements. Lehman (2004) does not suggest replacing prescription medication, but rather to assess the child's diet and individual needs when considering adding the aforementioned alternatives. All children, and especially those with a chronic condition, should be on a daily vitamin that contains the appropriate amounts of vitamins $\mathrm{A}, \mathrm{B}, \mathrm{C}$, D, E, and K, folic acid, iron, and calcium. Again, it is important to consult with a physician because large amounts of some vitamins (e.g., A and D) can cause severe illness and even death.

When considering supplements, it is important to remember that "all-natural" does not necessarily mean safe. One supplement that has been shown to be of benefit to people with arthritis is glucosamine, an ingredient used to manufacture cartilage. Omega3 fatty acids are another supplement that has been recommended for people with arthritis. However, early studies in the 1980s showed initial improvement in six to eight weeks with a slow return to impairment in the long run (Lehman, 2004). Additionally, patients were consuming 10 or more capsules a day in order to reach the claimed effect. What is important to remember is that any agent with demonstrative clinical effects can have possible side effects (Lehman, 2004).

In addition to the claimed effects of medication and supplements, therapeutic exercise has been shown to be beneficial to children with JRA. Both physical and occupational therapy can make it easier to move difficult joints. While medication helps reduce pain and inflammation, only therapeutic exercise can restore lost motion in a joint 
(Lehman, 2004). Examples include range-of-motion exercised used to keep joints flexible and make it easier for children to perform daily living skills, such as eating, writing, and dressing.

Other daily activities include hot and cold treatments and massages. Heat treatment is used for decreasing the rigidity of the joints while increasing the flexibility of the fibrous tissue in the joint capsules and tendons. Applying heat treatment before therapeutic exercises will increase the efficiency of the treatment. Cold treatment, on the other hand, is used for analgesic and vasoconstriction purposes in inflamed joints. Daily massages can help with pain and prevent adhesions in the subcutaneous tissues (Lehman, 2004). Field and colleagues (1997) found that children with mild to moderate JRA who were massaged 15 minutes a day for 30 days reported a decrease in pain, congruent with parent- and physician-reports. Furthermore, there was also a reduction in anxiety and cortisol levels as compared to the control group.

Another option that a physical or occupational therapist may recommend is a splint or orthotic, often used to help keep joints in the correct position and relieve pain. If a joint is at risk of becoming permanently deformed, a splint may help position and stretch it back to its normal position. Some commonly used splints include knee extension splints, wrist extension splints, and ring splints for the fingers.

In sum, the best or optimal treatment for JRA remains elusive in many regards and will continue to pose a challenge to clinicians. Our inability to predict individual outcomes with $100 \%$ accuracy remains a barrier to optimal disease management. Thus, additional studies on factors associated with favorable and unfavorable prognoses will be invaluable in guiding the most suitable and appropriate treatment. 


\section{Psychological Comorbidity in JRDs}

The unpredictable course and painful nature of JRDs can produce stress and increase the experience of emotional difficulties for both the children and their families. The role of psychological variables in JRD has been examined extensively, and in general, studies indicate that children and adolescents diagnosed with a JRD are at increased risk for further psycho-social adjustment problems, including depression, anxiety, and social withdrawal (Chaney et al., 1996; Reiter-Purtill et al., 2003; Vandvik, 1990). Similarly, parents of children with a chronic illness have been found to demonstrate increased negative affect (Barlow et al., 1998). This literature is reviewed in more detail as follows.

\section{$\underline{\text { Parent Adjustment }}$}

Because parents of children with a chronic illness must also adjust to their child's illness in addition to dealing with the financial burden associated with treatment, they may be impacted in ways quite similar to their children. For example, Barlow and colleagues (1998) found parents of children with JRA to experience increased feelings of guilt, anxiety, anger, hopelessness, and isolation. Moreover, parents of children with JRA tend to report a significant amount of illness-related stress, including fears regarding their child's future, school difficulties, and problems managing the prescribed treatment regimen (Degotardi, Revenson, \& Ilowite, 1999). A perceived lack of control and the inability to care for the child can negatively impact a parent's self-esteem (White et al., 2005). Although the majority of studies have focused on maternal adjustment, McNeill (2004) and Hovey (2005) found that fathers of children with JRA reported higher levels 
of emotional distress and concerns over their child's illness compared to normative groups of fathers.

Although parents of children with a chronic illness are generally at greater risk for a variety of emotional problems, poor psychological adjustment is not inevitable. Instead, a number of variables, such as the child's perception of pain and functional ability (Timko, Stovel, \& Moos, 1992b) and the parent's perception of stress, control, and other cognitive factors can either protect or contribute to the risk of adjustment problems in both children and their parents (Andrews, Chaney, Mullins, Hommel, Wagner, \& Jarvis, 2009; Chaney et al., 1997; Manuel, 2001). For instance, increased perceptions and demonstrations of overt pain by children with JRA have been associated with poorer psychological functioning among parents (Timko et al., 1992b). Maternal education and appraisal of the impact of the child's illness on the family have been shown to buffer against psychological distress (Manuel, 2001). That is, more positive appraisals were associated with decreased distress, even when illness stress was high, and higher levels of education were associated with decreased distress, even when daily hassles stress was high. Of note, a longitudinal study by Frank and colleagues (1998) found that maternal depression and overall parent distress were associated with behavioral problems in children with JRA and juvenile diabetes. Thus, based on a subsampling of recent work, it appears that not only does parent adjustment contribute to child outcomes, but also constitutes an important area of examination apart from child adjustment.

\section{Child Adjustment}

A substantial number of studies have examined the psychosocial adjustment and coping of children and adolescents with JRA, with mixed results. For example, an early 
study by Kellerman and colleagues (1980) found no significant differences between a group of 349 healthy adolescents and 168 adolescents with various chronic illnesses (e.g., JRDs, cancer, cystic fibrosis, diabetes) on measures of anxiety or self-esteem (Kellerman, Zeltzer, Ellenberg, Dash, \& Rigler, 1980). Moreover, a more recent study by Noll and colleagues (2000) compared 74 children with JRA and 74 healthy controls and found no significant differences on any measures of social and emotional functioning, with both groups scoring in the normative range.

Other investigators, however, have found an increased rate of poor psychological adjustment for children and adolescents who view their illness as negatively affecting their life (Timko, Baumgartner, Moos, \& Miller, 1993) and experiencing more severe functional losses (Timko, Stovel, Moos, \& Miller, 1992a). In general, children and adolescents with JRA who report several negative disease experiences have been found to express perceptions of decreased competency in athletic abilities, poor peer relationships, and feelings of being less attractive (Ennett, DeVellis, Earp, Kredich, Warren, \& Wilhelm, 1991).

Likewise, Mullick, Nahar, and Haq (2005) compared 40 children with JRA to 40 healthy control children and found that those with JRA were significantly more likely to have a depressive disorder (15\%) compared to the age- and sex-matched healthy control children (0\%). In a meta-analytic review, LeBovidge and colleagues (2003) examined adjustment problems among children with JRA and concluded that these children were at increased risk of for internalizing symptoms, but not for externalizing symptoms or poor self-concept. 
Although it appears that children and adolescents with JRA do nearly as well as their healthy peers, longitudinal studies indicate that they are at increased risk for higher functional loss, more physical disability, limited mobility to engage in exercise, and higher unemployment compared to healthy matched controls (e.g, Packham, Hall, \& Pimm, 2002; Peterson, Mason, Nelson, O’Fallon, \& Gabriel, 1997). Together, these prospective studies suggest that children adjust relatively well during developmental stages in which they are more dependent on parents or primary caregivers, but may have more difficulties adjusting as they transition to more independent and autonomous stages of development.

Similar to parent adjustment, poor psychological adjustment outcomes for children with JRA are not a guarantee. Cognitive appraisals, such as perceived illness uncertainty and illness intrusiveness, can serve to moderate the relationship between child distress and adjustment. White and colleagues (2005) found that children and adolescents who reported greater uncertainty regarding treatment and disease course had significant associations with parent distress and ultimately child depressive symptoms, although child illness uncertainty alone was not associated with adjustment difficulties. Moreover, parent support has been found to mediate child psychological adjustment even after controlling for disease severity, although peer social support was not a significant predictor of psychological adjustment (Varni et al., 1988). This study further elucidates the complex relationship between parental perceptions and child adjustment.

In sum, although children diagnosed with a chronic illness and their parents are generally at greater risk for a variety of difficulties (e.g., Barlow et al., 1998; Chaney et al., 1997; Ennett et al., 1991; White et al., 2005), these challenges are not inevitable. 
Instead, a number of evaluative variables, such as perceived control, perceived stress, perceived functional ability, and other cognitive factors function to protect or exacerbate the likelihood of parent and child adjustment problems (e.g., Manuel, 2001; Timko et al., 1992b; White et al., 2005). To set the stage for the current thesis project, the next section will discuss a specific model of parent and child adjustment to chronic illness, namely the transactional stress and coping model.

\section{Transactional Stress and Coping Model}

As previously noted, JRDs can involve considerable psychosocial and physical challenges, often creating potential stressors to which the children and families strive to adapt (e.g., Thompson, 1985). Thompson and colleagues (1992) developed the transactional stress and coping (TSC) model, which details the relationship between psychosocial outcomes of parents and children with a chronic illness (Thompson, Gustafson, Hamlett, \& Spock, 1992). The model proposes that adjustment to the illness is not direct, but rather is a complex function of the transactions between illness parameters (illness type and severity), demographic parameters (child's age, gender, and SES), and child and maternal adaptational processes (Thompson et al., 1993). Because child and maternal adaptational processes are the model's primary focus, they are hypothesized to be associated with adjustment beyond the contribution of illness and demographic parameters.

The TSC model incorporates Lazarus and Folkman's (1984) theoretical stance, where adjustment to a stressor (i.e., chronic illness) is mediated by the use of different coping processes that are guided by adaptational processes. The first and primary 
component is the cognitive processes of stress appraisal, expectations of treatment efficacy, and health locus of control.

Studies have repeatedly demonstrated the transaction between child and parent distress in predicting illness-related outcomes (e.g., Hocking \& Lochman, 2005; Thompson et al., 1993; Thompson et al., 1999; White et al., 2005). For instance, in a sample of children with spina bifida, Holmbeck and colleagues (2002) found that elevated levels of parental overprotection were significantly related to less autonomy and more externalizing behavior problems in their children. In addition to their behaviors, parental beliefs (e.g., perceived child vulnerability) have been associated with increased levels of illness uncertainty in adolescents with Type I diabetes mellitus (Mullins et al., 2007). In fact, one of the single most reliable predictors of a child's adjustment to a chronic illness is parent adjustment (Mullins \& Chaney, 2001).

The findings described above provide support for the transactional nature of parent and child adjustment to chronic illness, including JRDs. Indeed, they suggest that parent and child adjustment are interrelated and influence each other in a reciprocal fashion (Mullins, Fuemmeler, Hoff, Chaney, Van Pelt, \& Ewing, 2004). However, the literature has largely focused on the cross-sectional relationship between parent and child adjustment, yet important questions regarding the longitudinal association and temporal nature of this relationship remain unanswered. Therefore, the primary focus of the present study will be to address this gap in the literature and attempt to delineate the causal nature of the parent-child distress relationship in children with a JRD.

\section{Chapter Summary}


Although typically considered a disease of older adults, each year approximately 300,000 children in the United States are diagnosed with some form of arthritis or rheumatic disease (Lehman, 2008). Despite the psychosocial and physical challenges faced by children diagnosed with a JRD and their families, both must attempt to adjust in order to increase their likelihood of a positive adjustment outcome. Although children with a JRD are impacted across several domains, their parents also experience difficulties, including emotional problems and financial hardship. Consistent with the transactional stress and coping model, a child's adjustment to a JRD is significantly impacted by parent adjustment, and vice versa. Although there is large support for the parent-child distress relationship in cross-sectional studies across a variety of pediatric chronic illnesses, longitudinal investigations remain to be examined. Moreover, it is still unknown as to which variable, parent distress versus child distress, temporally precedes the other. The current study will address these questions by examining the longitudinal parent-child distress relationship over the course of a year, as well as investigating whether one variable is statistically dominant, or temporally precedent. 


\section{CHAPTER III}

\section{PRESENT STUDY}

Based on the aforementioned review of the literature, it is apparent that children diagnosed with a JRD are at risk for psychosocial adjustment problems, including depression and anxiety, behavioral issues, and social withdrawal. Similarly, parents of children with a chronic illness also face difficulties, such as depression and financial hardship. Although empirical investigations have reliably established the transactional nature of parent-child adjustment outcomes, the predominant direction of this relationship is not known. In other words, extant studies in the child chronic illness literature consistently reveal a reciprocal link between parent and child distress; however, no known study exists that indicates whether parent and child distress share equal valence in this transactional process, or if one is statistically predominant. Delineating the nature of the parent-child distress relationship could yield a variety of conceptual, empirical, and research implications. In particular, determining directionality could make significant contributions to existing conceptual models of parent and child adjustment to chronic illness. Further, clarifying the directional nature of this process could guide the focus of clinical interventions and standard care practices for chronically ill children and their families.

The purpose of the current study is to address this gap in the literature by examining the longitudinal nature of the association between parent and 
child distress in a sample of youths diagnosed with JRD and their parents. Specifically, using a cross-lagged panel correlation design (Kenny, 1975), the present study will explore the temporal precedence of parent distress and child distress in the parent-child adjustment process over the course of one year. Accordingly, the following are hypothesized:

Hypothesis 1: Consistent with the transactional stress and coping model, it is hypothesized that parent distress, as measured by the Brief Symptom Inventory (BSI) will be positively related to child distress, as measured by the Child Depression Inventory (CDI), at both time points.

Hypothesis 2: Parent distress and child distress will be positively associated with one another over the one-year period.

Given the exploratory nature of this study, however, no specific directional hypotheses were made regarding the temporal precedence of parent or child distress. It was anticipated that the cross lagged panel analysis would yield evidence indicating the temporal nature of the parent-child adjustment relationship in a sample of children with a JRD and their parents. 


\section{CHAPTER IV}

\section{METHOD \\ Participants and Procedure}

Participants were 37 (15 females; 22 males) children and adolescents between the ages of nine and $17(M=13.7 ; S D=2.3)$, who were diagnosed with juvenile rheumatoid arthritis (JRA; $n=22)$, systemic lupus erthematosus (SLE; $n=9$ ), juvenile dermatomyositis (JDMA; $n=4)$, or juvenile spondylarthropathies (JAS; $n=2$ ), and their parents. Participants were from a larger cross-sectional sample of 53 youth (see Andrews et al., 2009) who agreed to participate in a one-year follow-up. The majority of participants identified as Caucasian $(19 \% ; n=51)$, followed by Native American $(11 \% ; n$ =30), Biracial (3\%; $n=8)$, African American $(2 \% ; n=5)$, Hispanic American $(1 \% ; n=$ $3)$, and Asian $(1 \% ; n=3)$. Average illness duration for this sample was 2.8 years $(S D=$ 3.4). See Table 1 for a summary of participant demographics.

Participants were recruited from the Pediatric Rheumatology clinic at Children's Hospital of Oklahoma. Inclusion criteria for participation were as follows: 1) a diagnosis of one of the above-mentioned JRDs and between the ages of nine and 17, and 2) the duration of the illness-related symptoms of at least one year. Exclusion criteria were as follows: 1) parent or child demonstrated comorbid cognitive deficit (e.g., intellectual disability), 2) child demonstrated comorbid chronic illnesses, and 3) parent or child are non-fluent English speakers. 
Once the pediatric rheumatologist determined that an individual was eligible for participation, a research assistant recruited each participant. Institutional Review Board approval for the present study was obtained, and written informed assent and consent were also obtained from each participant, parent, or legal guardian. Participants completed packets in either the clinic or at home and then returned them via postage-paid mail. Questionnaire packets were identical for both time points. Upon completion, participants were compensated with a $\$ 10$ check.

\section{Measures}

\section{Background Information Questionnaire}

The background information questionnaire ascertained the following information: child's current age and grade, parent's current age, child and parent's ethnicity, child's living arrangement, the highest grade completed and occupations of the child's parents, parent marital status, annual household income, and child history of psychoactive medication and/or psychological counseling/therapy (see Appendix A).

\section{Physician-Report Measure}

Physician-Rated Functional Disability (PRFD; Hochberg, Chang, Dwosh, Lindsey, Pincus, \& Wolfe, 1992). The pediatric rheumatologist completed a provider questionnaire to obtain information regarding diagnosis, date of diagnosis, and functional disability. PRFD was determined by rheumatologist classification of children into one of four functional classes ranging from class I (limited or no disability in vocational and self-care activities) to class IV (severe disability) (e.g., Hochberg et al., 1992). This classification system has been shown to be a valid index of functional disability in children with JRD (Baildam, Holt, Conway, \& Morton, 1995). The rheumatologist 
provided disability classifications following a routine physical examination. Data indicated a relatively low level of functional disability $(M=1.46, S D=.65)$ in the current sample (see Appendix B).

\section{$\underline{\text { Child-Report Measures }}$}

Children's Depression Inventory (CDI; Kovacs, 1992). The CDI is a well known 27-item self-report measure of depressive symptoms over a two-week period. Severity ranges from 0 ("I am sad once in a while") to 2 ("I am sad all the time"), with higher summed scores indicating greater depressive symptoms (possible range $=0-54$ ). The CDI has been shown to be a reliable measure, with internal consistency reliability ranging from .71 to .89 (Kovacs, 1992). Internal reliabilities for the present sample were .87 and .82 for T1 and T2, respectively. Average CDI scores for the present sample were 8.14 $(S D=8.90 ;$ range $=0-27)$ at Time $1\left(C_{1}\right)$ and $7.42(S D=5.74 ;$ range $=0-25)$ at Time 2 $\left(\mathrm{C}_{2}\right)$. Of note, the percentage of the sample with clinically elevated depressive symptoms (e.g., CDI total > 13) was $16 \%$ at $\mathrm{T} 1$ and $19 \%$ at T2, indicating that the majority of children and adolescents endorsed mild to moderate depressive symptoms (see Appendix C).

Juvenile Arthritis Functional Assessment Report-Child (JAFAR-C; Howe et al., 1991). The JAFAR-C is a 23 -item measure assessing subjective estimates of functional ability. Participants rate how often they are able to perform 23 daily tasks (e.g., buttoning a shirt, getting into bed $)$ on a 3 -point Likert scale $(0=$ all the time; $2=$ almost never $)$, with higher sum scores indicating greater disability (possible range $=0-46$ ). Good construct validity and acceptable internal consistency has been demonstrated (Howe et al., 1991). Cronbach's alpha for $\mathrm{T} 1$ and $\mathrm{T} 2$ in the present study was .90 and .95, 
respectively. The average JAFAR-C score for this sample of children was 4.85 (SD $=5.83$; range $=0-23)$ at $\mathrm{T} 1$ and $2.19(S D=5.15 ;$ range $=0-27)$ at $\mathrm{T} 2$ (see Appendix $\mathrm{D})$. Parent-Report Measures

Brief Symptom Inventory (BSI; Derogatis, 1993). The BSI is a 53-item self-report measure that assesses adult global psychological adjustment. Respondents rate the degree to which psychological symptoms (e.g., poor appetite, difficulty making decisions, feelings of guilt) have caused distress during the past seven days. Items are rated from 1 (not at all) to 4 (extremely), and then scores are summed and divided by the total number of items to obtain a Global Severity Index (GSI; possible range $=0-4$ ). The BSI has been used extensively as a measure of parent emotional adjustment in studies examining parent contributions to child adaptation and outcome to chronic illness (Mullins et al., 1995; Wagner et al., 2003; White et al., 2005). The BSI has been found to have satisfactory internal consistency, ranging from .71 to .85 (Derogatis \& Melisaratos, 1983). For this sample, Cronbach's alpha was .97 at T1 and .98 at T2. Mean GSI scores at Time $1\left(\mathrm{P}_{1}\right)$ and Time $2\left(\mathrm{P}_{2}\right)$ were $.54(S D=.60 ;$ range $=0-3.13)$ and $.46(S D=.53 ;$ range $=0-2.11)$, respectively (see Appendix E).

Juvenile Arthritis Functional Assessment Report-Parent (JAFAR-P; Howe et al., 1991). The Juvenile Arthritis Functional Assessment Report-Parent (JAFAR-P; Howe et al., 1991) is the parent version of the JAFAR-C with identical items and scoring. Good construct validity and acceptable internal consistency has been demonstrated (Howe et al., 1991). Cronbach's alpha was .92 at T1 and .93 at T2 in the present study. Average JAFAR-P scores for this sample at $\mathrm{T} 1$ and $\mathrm{T} 2$ were $4.42(S D=6.06$; range $=0-22)$ and $3.27(S D=5.74 ;$ range $=0-27)$, respectively (see Appendix F). 


\section{CHAPTER V}

\section{RESULTS}

\section{$\underline{\text { Overview of Analyses }}$}

Cross-lagged panel correlation (Kenny, 1975), the primary analysis in this paper, is a quasi-experimental design that attempts to rule out alternative explanations (i.e., spuriousness) to a causal inference according to time precedence. Although true experiments control for spuriousness by random assignment to conditions, practical and ethical reasons did not allow for manipulation or random assignment of the variables in the current study. Cross-lagged analysis necessitates that two constructs be measured at two different time points. The two constructs (i.e., CDI and BSI) and two time points (i.e., T1 and T2) generate four variables $\left(\mathrm{C}_{1}, \mathrm{C}_{2}, \mathrm{P}_{1}\right.$, and $\left.\mathrm{P}_{2}\right)$, which produce six correlations (refer to Figure 1): two autocorrelations $\left(\mathrm{C}_{1} \mathrm{C}_{2}\right.$ and $\left.\mathrm{P}_{1} \mathrm{P}_{2}\right)$, two synchronous correlations $\left(\mathrm{C}_{1} \mathrm{P}_{1}\right.$ and $\left.\mathrm{C}_{2} \mathrm{P}_{2}\right)$, and two cross-lagged correlations $\left(\mathrm{C}_{1} \mathrm{P}_{2}\right.$ and $\left.\mathrm{P}_{1} \mathrm{C}_{2}\right)$.

According to Kenny (1975), three fairly strict assumptions must be satisfied to allow for appropriate interpretation of the temporal relationship between variables:

synchronicity (i.e., variables are measured simultaneously at both times), reliability and stability of the measures over time, and stationarity (i.e., a lack of change in the strength/direction of correlations over time). Although readers are referred to Kenny (1975) for a comprehensive overview of the cross-lagged panel method, a brief description of the aforementioned assumptions will be discussed. 
With regard to synchronicity, it is typically the easiest assumption to meet as long as the variables are measured simultaneously and do not rely on retrospect or aggregation across multiple points in time. Reliability and stability refer to the internal consistency and test-retest correlation coefficients of each measure or variable at both time points. Stationarity, on the other hand, means that the causal equation for each variable remains the same at both points of measurement. Because it is believed that the same variable is repeatedly measured in the cross-panel design, it is reasonable to believe that the causes of the variable would not have changed and that the issue would then become one of strength between the causes (Kenny, 1975). Stationarity and stability should be distinguished from each other. Stationarity refers to the lack of change in the strength and direction of the causes of a variable over time, while stability refers to the lack of change over time of the empirical values of each variable.

The hypotheses tested in the cross-lagged method are the nonsignificant difference between the synchronous correlations to test for stationarity and the nonsignificant difference between the cross-lagged correlations to test for spuriousness. As such, Fisher's $r$-to- $z$ transformation cannot be used to test for the significance of the differences because the correlations are correlated with one another. Therefore, the Pearson-Filon $r$-to- $z$ transformation was used (Kenny, 1975) in order to account for the correlations between one another. In sum, a cross-lagged panel design was used in the current study to examine the temporal precedence and predictive association between parent distress and child distress in JRDs over a one-year time period. Preliminary Analyses 
No significant differences were observed on demographic or disease parameters between participants who completed packets at both time points and those who did not, or between those who completed packets in the clinic versus returned them by mail (all $p$ 's > .05).

A series of bivariate correlations were conducted to identify demographic (i.e., age and sex) and disease variables (i.e., illness duration, PRFD, JAFAR-P, and JAFARC) as potential covariates in the cross-lagged panel analysis. Kenny (1975) recommends that suitable covariates should demonstrate at least moderate associations (i.e., .30 or greater) with the target variables at both time points. As such, covariates were chosen based on significant correlations between demographic or illness variables and the dependent variables (i.e., CDI and BSI). Correlation analyses revealed that illness duration, PRFD, JAFAR-P, and all of the demographic variables were not significantly related to CDI scores at either time point. Only T1 JAFAR-C significantly correlated with CDI at both time points $(r=.41, p<.01$ and $r=.41, p<.01)$. T1 JAFAR-C was also correlated significantly with BSI at T2 $(r=.46, p=.004)$, but only minimally at T1 ( $r=$ $.20, p=.24)$. Therefore, since T1 JAFAR-C demonstrated a moderate association with three out of four preliminary analyses, it was controlled for in all subsequent cross-lagged panel analyses via conducting partial correlations.

\section{Cross-Lagged Panel Analysis}

As previously stated, three assumptions must be met before examining the crosslagged correlations: synchronicity, reliability and stability, and stationarity. Synchronicity is typically the easiest of the assumptions to meet and was satisfied by simultaneous administration of the CDI and BSI at both time points. Reliability and Stability were 
determined first by examining internal consistency reliabilities at T1 and T2. Reliability estimates indicated good to excellent internal consistencies for both the CDI $(\mathrm{T} 1=.91$, $\mathrm{T} 2=.82)$ and $\mathrm{BSI}(\mathrm{T} 1=.97, \mathrm{~T} 2=.97)$ at both time periods. In addition, comparison of the test-retest autocorrelations (i.e., $\mathrm{C}_{1} \mathrm{C}_{2}$ vs. $\mathrm{P}_{1} \mathrm{P}_{2}$ ) revealed a nonsignificant difference (see Table 2), demonstrating measurement stability over the one-year interval. Stationarity requires comparison of synchronous correlations (i.e., $\mathrm{C}_{1} \mathrm{P}_{1}$ and $\mathrm{C}_{2} \mathrm{P}_{2}$ ) to determine whether significant changes are observed in the cross-sectional parent-child distress associations from T1 to T2. Pearson-Filon $r$-to- $z$ comparisons revealed that synchronous correlations did not differ significantly (see Table 2), indicating perfect stationarity in the data (see Chaney et al., 2004 and Kenny, 1975 for calculations). Further, effect sizes were calculated for all cross-lagged panel analyses. Specifically, Cohen's $q$ was used as the measure of effect size between correlations after standardization with the following conventions being employed: $.10=$ small, $.30=$ medium, $.50=$ large (see Table 2; Cohen, 1988)

Cross-lagged correlation comparisons. The statistical dominance of parent distress vs. child distress was examined by comparing the magnitude of the cross-lagged correlations (e.g., $\mathrm{C}_{1} \mathrm{P}_{2}$ vs. $\mathrm{P}_{1} \mathrm{C}_{2}$ partial correlations in Figure 1). Pearson-Filon $r$-to- $z$ comparisons found a significant cross-lagged correlation difference $(z=1.98, p=.02)$, indicating that the longitudinal association between $\mathrm{T} 1$ parent distress and T2 child distress $\left(\mathrm{P}_{1} \mathrm{C}_{2}\right)$ was significantly greater than the association between $\mathrm{T} 1$ child distress andT2 parent distress $\left(\mathrm{C}_{1} \mathrm{P}_{2}\right)$. Thus, results of the cross-lagged correlation analysis revealed the statistical dominance of $\mathrm{P}_{1} \mathrm{C}_{2}$ relative to $\mathrm{C}_{1} \mathrm{P}_{2}$, indicating that parent distress was temporally antecedent to child distress over the one-year time period. Importantly, 
the longitudinal parent-child distress correlation $\left(\mathrm{P}_{1} \mathrm{C}_{2}\right)$ was greater than both of the cross-sectional correlations $\left(\mathrm{P}_{1} \mathrm{C}_{1}\right.$ and $\left.\mathrm{P}_{2} \mathrm{C}_{2}\right)$. According to Kenny (1975), such findings provide additional support for inferring relative temporal precedence. 


\section{CHAPTER VI}

\section{DISCUSSION}

The present study was designed to examine the longitudinal relationship between parent and child distress in a sample of children and adolescents diagnosed with a JRD and their parents. Two specific hypotheses were proposed: 1) increased parent distress would be significantly positively associated with child distress at both time points; and 2) parent distress and child distress would be significantly positively associated with one another over the one-year period. Lastly, given the exploratory nature of the study, no specific directional hypotheses were made regarding the temporal precedence of parent distress versus child distress. It was anticipated that that cross-lagged panel analysis would yield evidence indicating the temporal nature of this relationship.

Consistent with hypotheses and existing literature demonstrating transactional parent-child distress relations (e.g., Chaney et al., 1997; Hocking \& Lochman, 2005; Kazak, Kassam-Adams, Schneider, Zelikovsky, Alderfer, \& Rourke, 2006; Mullins \& Chaney, 2001; Thompson, et al., 1999; Thompson, et al., 1994; Thompson \& Gustafson, 1996; Wagner, et al., 2003; White et al., 2005), partial correlations revealed significant cross-sectional parent-child distress associations at both time points. In addition, results revealed a significant longitudinal association between $\mathrm{T} 1$ parent distress and $\mathrm{T} 2$ child distress, although there was a nonsignificant association between T1 child distress and T2 parent distress. These relationships were observed after controlling for JAFAR-C at T1. 
Consistent with Kenny's (1975) recommendations that three assumptions be met before comparing the cross-lagged correlations, measures of parent and child distress were simultaneously administered at both time points (i.e., synchronicity), both measures demonstrated good to excellent internal consistency and stability over the one-year period (i.e., reliability and stability), and Pearson-Filon r-to-z transformation revealed that the synchronous correlations did not differ significantly (i.e., stationarity). More importantly, the exploratory cross-lagged correlation analysis demonstrated the statistical dominance of parent distress relative to child distress in the parent-child distress association over the one-year time period. In other words, whereas T1 parent distress predicted T2 child distress, initial levels of child distress did not significantly predict parent distress one year later.

\section{Strengths and Limitations}

Currently, there are no known studies in the extant literature that have addressed directionality in existing theoretical models of parent and child adjustment to JRDs, or chronic illness in general (e.g., Kazak et al., 2006; Thompson \& Gustafson, 1996). That parent distress was found to temporally precede child distress over time addresses a gap in the pediatric chronic illness literature, suggesting that importance of the family system, and more specifically parent-focused interventions (e.g., Kazak et al. 2005; Sahler et al., 2005; Streisand, Rodrigue, Houck, Graham-Pole, \& Berlant, 2000). These will be discussed in more detail below.

Further, the current study utilized both parent- and child-report measures of distress and functional ability. Although previous research has largely focused on mother's perceptions of their child's adjustment, other studies have demonstrated a 
significant discrepancy between parent- and child-report of child distress (e.g., Bennett, 1994; Ennett et al., 1994). Although reports are subjective, the present study provides a more accurate portrayal of child distress by using self-report measures.

Likewise, the present study included both objective, physician-rated disease severity and functional ability, and subjective, parent-reported perceptions of their child's disease severity. Inclusion of both measures is theoretically important because physicianrated disease severity, although objective, has been shown to be less predictive of parent distress compared to parent perceptions of their child's illness severity (e.g., Hocking \& Lochman, 2005; Thompson et al., 1993; Thompson et al., 1999; White et al., 2005). Indeed, objective and subjective ratings of disease severity and associated functional ability in JRDs are independently related to adjustment outcomes (Ravelli, Viola, Ruperto, Corsi, Ballardini, \& Martini, 1997).

The findings of the present study must be qualified by several limitations. First, attrition rates resulted in a modest sample size. Similarly, due to the sample size, results of the present study should be interpreted with caution as statistical power is a concern. Further, interpretation and generalization of these results remain somewhat limited by a relatively homogenous, self-selected sample of participants that may have resulted in significant associations between parent and child distress. However, this concern was attenuated somewhat by the inclusion of a culturally heterogeneous sample and an observed attrition rate (29\%) that approximated those seen in other longitudinal studies with pediatric and adult populations (e.g., Chaney et al., 2004; Janus \& Goldberg, 1997). Additionally, no significant differences were observed between participants who completed both time points and those who did not on demographic, disease, or distress 
variables. Nevertheless, findings in the present study are based on a fairly modest sample of participants with JRDs from similar sociocultural backgrounds, and caution should be exercised in generalizing the findings to other pediatric illness groups and more diverse groups of individuals with a JRD.

Another limitation involves the use of self-report inventories that may have resulted in spurious correlations due to shared method variance rather than actual associations between the target variables. This issue was attenuated somewhat by the inclusion of both parent- and child-report measures.

The present study also included children in both pre-adolescent and adolescent phases of development. Given that the developmental challenges of these groups are fairly different, such as emerging independence and increased social pressures with age, it is possible that illness-related adjustment issues may be different at various stages of development. Unfortunately, extensive demographic information was not collected from parent participants. As such, potential parent demographic data that may have aided in interpretation of the current findings were unavailable.

Finally, the cross-lagged panel method is a quasi-experimental design and unlike true experimental methods, causal inferences are based on the statistical dominance of one variable relative to another variable over time (Kenny, 1975). Similar to other causal modeling approaches, concerns have been raised regarding the validity of the crosslagged method in making causal inferences (e.g., Rogosa, 1988). Such criticisms center around making causal inferences based on data that fail to meet the three assumptions (i.e., synchronicity, reliability and stability, and stationarity) on which the cross-lagged method is based. Although data in the current study satisfied these assumptions, it cannot 
be said for certain that parent distress caused child distress. In other words, levels of parent distress measured initially in this study may have been preceded by child distress occurring prior to the start of our investigation. Because true causality cannot be determined to the same extent as in true experimental designs and in the absence of a causal baseline, the present findings can only be viewed as suggestive evidence for the temporal predominance of parent distress in the parent-child distress process (cf. Burns, Kubilus, Bruehl, Harden, \& Loftland, 2003).

\section{Implications and Recommendations for Future Research}

The aforementioned limitations nothwithstanding, the finding that parent distress was temporally antecedent to child distress has a number of conceptual and treatment implications. First, results of the present study add to the extent literature on the transactional nature of parent-child distress. Although preliminary and currently exclusive to JRDs, this finding may further delineate the directionality in the parent-child distress interaction for other pediatric illnesses.

Second, the findings underscore the salience of the family system as the target of empirical investigation and clinical intervention efforts in the JRD population. Currently, children and adolescents with a JRD are the primary focus of assessment and available resources. However, these results suggest that child distress may reflect the downstream effects of parent distress, and as such, the data suggest that attention and early intervention efforts acknowledge the importance of parents and their distress and coping when addressing the child's adjustment concerns. For instance, this may be done during the child's routine medical visits, in which parents could complete brief measures of psychological adjustment (e.g., Beck Depression Inventory) in the waiting room. This 
finding may also provide initial support for providing increased insurance coverage and reimbursement for parent- and family-focused interventions because many insurance carriers do not adequately cover psychotherapy for the parent unless the patient (i.e., child) is also present (Noll \& Fischer, 2004).

This is not to suggest that other family members (e.g., siblings, grandparents, and other caregivers) should not receive support services if they are needed. However, to the extent that limited resources are available for psychosocial services in a standard care system, preliminary data from the present study propose that primary intervention efforts might be most judiciously directed toward parents. This is especially the case in JRDs because children are often diagnosed at a young age (e.g., 18 months to 5 years) but unable to actively participate in therapy due to their developmental status. Current findings lend support for parent-focused interventions as a proactive attempt to protect the child and parent from further distress in the future. In the meantime, social and family support for parents of children with a JRD may provide a buffer against stress and reduce adjustment difficulties (Lazarus \& Folkman, 1984), further protecting the child from distress. In fact, Ireys and colleagues (1996) paired mothers of children newly diagnosed with JRA with mothers of young adults with JRA and found decreased mental health problems compared to unpaired controls.

Recommendations for future research include examining JRD populations and other illness groups comprised of larger sample sizes, and ideally from multiple sites to allow for a more heterogeneous sample and increase generalizability. Additionally, it would be beneficial to examine potential differences in the longitudinal parent-child distress process across developmental stages. Subsequent investigations should gather 
more extensive demographic information from parent participants in order to aid in the interpretation of findings and examine any potential confounds.

In general, results of the present study provide initial support for the statistical dominance of parent distress relative to child distress in the parent-child distress process in a sample of children and adolescents with a JRD. The present findings are also consistent with the extant literature demonstrating the transactional nature of the parentchild distress association in cross-sectional studies. Importantly, findings support increased attention given to the family system, specifically parents, in order to protect them and their children from additional stress associated with a pediatric chronic illness. 


\section{REFERENCES}

Allen, K., \& Shriver, M. (1998). Role of parent-mediated pain behavior management strategies in biofeedback treatment of childhood migraines. Behavior Therapy, 29, 477-490. doi:10.1016/S0005-7894(98)80044-0

Andrews, N., Chaney, J., Mullins, L., Hommel, K., Wagner, J., \& Jarvis, J. (2009). The differential effect of child age on the illness intrusiveness-parent distress relationship in juvenile rheumatic disease. Rehabilitation Psychology, 54, 45-50. doi:10.1037/a0014443

Baildam, E. M., Holt, P. J. L., Conway, S. C., \& Morton, M. J. S. (1995). The association between physical function and psychological problems in children with juvenile chronic arthritis. Rheumatology, 34, 470-477. doi:10.1093/rheumatology/34.5.470

Barlow, J., Harrison, K., \& Shaw, K. (1998). The experience of parenting in the context of juvenile chronic arthritis. Clinical Child Psychology and Psychiatry, 3, 445463. doi: $10.1177 / 1359104598033008$

Bennett, D.S. (1994). Depression among children with chronic medical problems: A meta-analysis. Journal of Pediatric Psychology, 19, 149-169. doi: 10.1093/jpepsy/19.2.149

Burns, J., Kubilus, A., Bruehl, S., Harden, N., \& Loftland, K. (2003). Do changes in cognitive factors influence outcome following multidisciplinary treatment for chronic pain? A cross-lagged panel analysis. Journal of Consulting and Clinical Psychology, 71, 81-91. doi: 10.1037/0022-006X.71.1.81 
Cassidy, J., \& Petty, R. (2001). The textbook of pediatric rheumatology $\left(4^{\text {th }}\right.$ ed.). Philadelphia: W.B. Saunders.

Chaney, J., Mullins, L., Frank, R., Peterson, L. Mace, L., Kashani, J., \& Goldstein, D. (1997). Transactional patterns of child, mother, and father adjustment in Insulindependent diabetes mellitus: A prospective study. Journal of Pediatric Psychology, 2, 229-244. doi:10.1093/jpepsy/22.2.229

Chaney, J., Mullins, L., Uretsky, D., Doppler, M., Palmer, W., Wees, S., et al. (1996). Attributional style and depression in rheumatoid arthritis: The moderating role of perceived illness control. Rehabilitation Psychology, 41, 205-223. doi:10.1037/0090-5550.41.3.205

Degotardi, P. J., Revenson, T. A., \& Ilowite, N. T. (1999). Family-level coping in juvenile rheumatoid arthritis: Assessing the utility of a quantitative family interview. Arthritis Care and Research, 12, 314-324. doi:10.1002/15290131(199910)12:5<314::AID-ART2>3.0.CO;2-V

Derogatis, L. (1993). The Brief Symptom Inventory: Administration, Scoring, and Procedures Manual. Minneapolis, MN: National Computer Systems, Inc.

Derogatis, L., \& Melisaratos, N. (1983). The Brief Symptom Inventory: An introductory report. Psychological Medicine, 13, 595-605. doi:10.1017/S0033291700048017

Dixon, K., Keefe, F., Scipio, C., Perri, L., \& Abernethy, A. (2007). Psychological interventions for arthritis pain management in adults: A meta-analysis. Health Psychology, 26, 241-250. doi:10.1037/0278-6133.26.3.241; 10.1037/02786133.26.3.241.supp 
Ennett, S., DeVellis, B., Earp, J., Kredich, D., Warren, R., \& Wilhelm, C. (1991). Disease experience and psychosocial adjustment in children with juvenile rheumatoid arthritis: Children's versus mother's reports. Journal of Pediatric Psychology, 16, 557-568. doi:10.1093/jpepsy/16.5.557

Feldman, B., Rider, L., Reed, A., \& Pachman, L. (2008). Juvenile dermatomyositis and other idiopathic inflammatory myopathies of childhood. The Lancet, 371, 22012212. doi:10.1016/S0140-6736(08)60955-1

Field, T., Hernandez-Reif, M., Seligman, S., Krasnegor, J., Sunshine, W., Rivas-Chacon, R., et al. (1997). Juvenile rheumatoid arthritis: Benefits from massage therapy. Journal of Pediatric Psychology, 22, 607-617. doi:10.1093/jpepsy/22.5.607

Flato, B., Aasland, A., Vinje, O., \& Forre, O. (1998). Outcome and predictive factors in juvenile rheumatoid arthritis and juvenile spondyloarthropathy. Journal of Rheumatology, 25, 366-375. Retrieved from http://jrheum.org/

Frank, R., Hagglund, K., Schopp, L., Thayer, J., Vieth, A., Cassidy, J., et al. (1998). Disease and family contributors to adaptation in juvenile rheumatoid arthritis and juvenile diabetes. Arthritis Care and Research, 11, 166-176. doi:0.1002/art.1790110304

Gil, K., Anthony, K., Carson, J., Redding-Lallinger, R., Daeschner, C., \& Ware, R. (2001). Daily coping practice predicts treatment effects in children with sickle cell disease. Journal of Pediatric Psychology, 26, 163-173. doi:10.1093/jpepsy/26.3.163

Hochberg, M. C., Chang, R. W., Dwosh, I., Lindsey, S., Pincus, T., \& Wolfe, F. (1992). The American College of Rheumatology 1991 revised criteria for the 
classification of global functional status in rheumatoid arthritis. Arthritis and Rheumatism, 35, 498-502. doi:10.1002/art.1780350502

Hocking, M.C., \& Lochman, J.E. (2005). Applying the transactional stress and coping model to sickle cell disorder and insulin-dependent diabetes mellitus: Identifying psychosocial variables related to adjustment and intervention. Clinical Child and Family Psychology Review, 8, 221-246. doi:10.1007/s10567-005-6667-2

Holmbeck, G. N., Johnson, S. Z., Wills, K. E., McKernon, W., Rose, B., Erklin, S., \& Kemper, T. (2002). Observed and perceived parental overprotection in relation to psychosocial adjustment in preadolescents with a physical disability: The mediational role of behavioral autonomy. Journal of Consulting and Clinical Psychology, 70, 96-110. doi:10.1037/0022-006X.70.1.96

Hovey, J. K. (2005). Father's parenting chronically ill children: Concerns and coping strategies. Issues in Comprehensive Pediatric Nursing, 28, 83-95. doi:10.1080/01460860590950863

Howe, S., Levinson, J., Shear, E., Hartner, S., McGirr, G., Schlulte, M., \& Lovell, D. (1991). Development of a disability measurement tool for juvenile rheumatoid arthritis. The Juvenile Arthritis Functional Assessment Report for children and their parents. Arthritis and Rheumatism, 34, 873-880. doi:10.1002/art.1780340713

Ilowite, N. (2002). Current treatment of juvenile rheumatoid arthritis. Pediactrics, 109, 109-115. doi:10.1542/peds.109.1.109

Ireys, H. T., Sills, E. M., Kolondner, K. B., \& Walsh, B. B. (1996). A social support intervention for parents of children with juvenile rheumatoid arthritis: Results of a 
randomized trial. Journal of Pediatric Psychology, 21, 633-641. doi: 10.1093/jpepsy/21.5.633

Janus, M., \& Goldberg, S. (1997). Factors influencing family participation in a longitudinal study: Comparison of pediatric and healthy samples. Journal of Pediatric Psychology, 22, 245-262. doi:10.1093/jpepsy/22.2.245

Kazak, A. E., Kassam-Adams, N., Schneider, S., Zelikovsky, N., Alderfer, M. A., \& Rourke, M. (2006). An integrative model of pediatric medical traumatic distress. Journal of Pediatric Psychology, 31, 343-355. doi:10.1093/jpepsy/jsj054

Kazak, A. E., Simms, S., Alderfer, M. A., Rourke, M. T., Crump, T., McClure, K., . . . Reilly, A. (2005). Feasibility and preliminary outcomes from a pilot study of a brief psychological intervention for families of children newly diagnosed with cancer. Journal of Pediatric Psychology, 30, 644-655. doi:10.1093/jpepsy/jsi051

Khan, M. (1993). Seronegative spondylarthropathies: Ankylosing spondylitis. In H.R. Schumacher, Jr., J. H. Klippel, \& W.J. Koopman (Eds.), Primer on the rheumatic diseases: Tenth edition (pp. 171-174). Atlanta, GA: Arthritis Foundation.

Kaplan, G., \& Delongis, A. (1983, August). Psychosocial factors influencing the course of arthritis: A prospective study. Paper presented at the meeting of the American Psychological Association, Anaheim, CA.

Kellerman, J., Zeltzer, L., Ellenberg, L., Dash, J., \& Rigler, D. (1980). Psychological effects of illness in adolescence: I. Anxiety, self-esteem, and perception of control. Journal of Pediatrics, 97, 126-131.

Kenny, D. (1975). Cross-lagged panel correlation: A test for spuriousness. Psychological Bulletin, 82, 887-903. doi:10.1037/0033-2909.82.6.887 
Kotaniemi, K., Kaipiainen-Seppänen, O., Savolainen, A., \& Karma, A. (1999). A population-based study on uveitis in juvenile rheumatoid arthritis. Clinical and Experimental Rheumatology, 17, 119-122. Retrieved from http://www.clinexprheumatol.org/

Kovacs, M. (1992). Children's Depression Inventory Manual. Toronto, Ontario: MultiHealth Systems, Inc.

Lazarus, R., \& Folkman, S. (1984). Stress, appraisal, and coping. New York, NY: Springer.

LeBovidge, J. S., Lavigne, J. V., Donenberg, G. R., \& Miller, M. L. (2003). Psychological adjustment of children and adolescents with chronic arthritis: A meta-analytic review. Journal of Pediatric Psychology, 28, 29-39. doi:10.1093/jpepsy/28.1.29

Lehman, T. (2008). A parent's guide to rheumatic disease in children. New York, NY: Oxford University Press.

Lehman, T. (2004). It's not just growing pains: A guide to childhood muscle, bone, and joint pain, rheumatic diseases, and the latest treatments. New York, NY: Oxford University Press.

Lehman, T. (1997). Connective tissue diseases and nonarticular rheumatism. In J. H. Klippel (Ed.), Primer on the rheumatic diseases: Eleventh edition (pp. 398-403). Atlanta, GA: Arthritis Foundation.

Lovell, D. (1997). Juvenile rheumatoid arthritis and juvenile spondyloarthropathies. In J. H. Klippel (Ed.), Primer on the rheumatic diseases: Eleventh edition (pp. 393398). Atlanta, GA: Arthritis Foundation. 
Manuel, J. (2001). Risk and resistance factors in the adaptation in mothers of children with juvenile rheumatoid arthritis. Journal of Pediatric Psychology, 26, 237-246. doi:10.1093/jpepsy/26.4.237

McNeill, T. (2004). Fathers' experience of parenting a child with juvenile rheumatoid arthritis. Qualitative Health Research, 14, 526-545.

doi: $10.1177 / 1049732303262374$

Mullick, M. S., Nahar, J. S., \& Haq, S. A. (2005). Psychiatric morbidity, stressors, impact, and burden in juvenile idiopathic arthritis. Journal of Health, Population, and Nutrition, 23, 142-149. Retrieved from http://www.icddrb.org/publication.cfm?classificationID=30

Mullins, L.L., \& Chaney, J.M. (2001). Pediatric psychology. In C.E. Walker \& M.C. Roberts (Eds.), Handbook of clinical child psychology ( $3^{\text {rd }}$ ed., pp. 910-927). New York: Wiley and Sons.

Mullins, L., Chaney, J., Hartman, V., Olson, R., Youll, L., Reyes, S., et al. (1995). Children and maternal adaptation to cystic fibrosis and insulin-dependent diabetes mellitus: Differential patterns across disease states. Journal of Pediatric Psychology, 20, 173-186. doi:10.1093/jpepsy/20.2.173

Mullins, L. L., Fuemmeler, B. F., Hoff, A., Chaney, J. M., Van Pelt, J., \& Ewing, C. A. (2004). The relationship of parental overprotection and perceived child vulnerability to depressive symptomatology in children with type 1 diabetes mellitus: The moderating influence of parenting stress. Children's Health Care, 33, 21-34. doi:10.1207/s15326888chc3301_2 
Mullins, L.L., Wolfe-Christensen, C., Pai, A.L., Carpentier, M.Y., Gillaspy, S., Cheek, J., et al. (2007). The relationship of parental overprotection, perceived child vulnerability, and parenting stress to uncertainty in youth with chronic illness. Journal of Pediatric Psychology, 32, 973-982. doi:10.1093/jpepsy/jsm044

Nicassio, P., Brown, G., Wallston, K., \& Szydlo, N. (1985, June). Arthritis experience and social support as predictors of psychological dysfunction in RA. Paper presented at the meeting of the Arthritis Health Professionals Association, Washington, DC.

Noll, R. B., \& Fischer, S. (2004). Commentary. Health and behavior CPT codes: An opportunity to revolutionize reimbursement in pediatric psychology. Journal of Pediatric Psychology, 29, 571-578. doi:10.1093/jpepsy/jsh059

Noll, R., Kozlowski, K., Gerhardt, C., Vannatta, K., Taylor, J., \& Passo, M. (2000). Social, emotional, and behavioral functioning of children with juvenile rheumatoid arthritis. Arthritis and Rheumatism, 43, 1387-1396. doi:10.1002/15290131(200006)43:6<1387::AID-ANR24>3.0.CO;2-C

O’Leary, A., Shoor, S., Lorig, L., \& Holman, H. (1988). A cognitive-behavioral treatment for rheumatoid arthritis. Health Psychology, 7, 527-544. doi:10.1037/0278-6133.7.6.527

Packham, J. C., Hall, M. A., \& Pimm, T. J. (2002). Long-term follow-up of 246 adults with juvenile idiopathic arthritis: Predictive factors for mood and pain. Rheumatology, 41, 1444-1449. doi:10.1093/rheumatology/41.12.1444

Peterson, L. S., Mason, T., Nelson, A. M., O’Fallon, W. M., \& Gabriel, S. E. (1997). Psychosocial outcomes and health status of adults who have had juvenile 
rheumatoid arthritis. Arthritis and Rheumatism, 40, 2235-2240. doi:10.1002/art.1780401219

Ratelli, A., Viola, S., Ruperto, N., Corsi, B., Ballardini, G., \& Martini, A. (1997). Correlation between conventional disease activity measures in juvenile chronic arthritis. Annuals of the Rheumatic Diseases, 56, 197-200. doi:10.1136/ard.56.3.197

Reiter-Purtill, J., Gerhardt, C., Vannatta, K., Passo, M., \& Noll, R. (2003). A controlled longitudinal study of the social functioning of children with juvenile rheumatoid arthritis. Journal of Pediatric Psychology, 28, 17-28. doi:10.1093/jpepsy/28.1.17

Rogosa, D. (1988). Myths about longitudinal research. In K. Schaie, R. Campbell, W. Meredith, \& S. Rawlings (Eds.), Methodological issues in aging research (pp. 171-209). New York: Springer.

Sahler, O. J. Z., Phipps, S., Mulhern, R. K., Noll, R. B., Varni, J. W., Fairclough, D. L., . .. Butler, R. W. (2005). Using problem-solving skills training to reduce negative affectivity in mothers of children with newly diagnosed cancer: Report of a multisite randomized trial. Journal of Consulting and Clinical Psychology, 73, 272-283. doi:10.1037/0022-006X.73.2.272

Streisand, R., Rodrigue, J. R., Houck, C., Graham-Pole, J., \& Berlant, N. (2000). Brief report: Parents of children undergoing bone marrow transplantation: Documenting stress and piloting a psychological intervention program. Journal of Pediatric Psychology, 25, 331-337. doi:10.1093/jpepsy/25.5.331 
Thompson, R. J. (1985). Coping with the stress of chronic childhood illnesses. In A.N. O’Quinn (Ed.), Management of chronic disorders of childhood (pp.11-41).

Boston: G.K. Hall.

Thompson, R. J., Gil, K., Burbach, D., Keith, B., \& Kinney, T. (1993). Role of child and maternal processes in the psychological adjustment of children with sickle cell disease. Journal of Consulting and Clinical Psychology, 61, 468-474. doi:10.1037/0022-006X.61.3.468

Thompson, R. J., \& Gustafson, K. E. (1996). Psychological adjustment of parents and siblings. Adaptation to Chronic Childhood Illness. Washington, DC: American Psychological Association.

Thompson, R. J., Gustafson, K. E., George, L. K., \& Spock, A. (1994). Change over a 12-month period in the psychological adjustment of children and adolescents with cystic fibrosis. Journal of Pediatric Psychology, 19, 189-203. doi:10.1093/jpepsy/19.2.189

Thompson, R. J., Gustafson, K. E., Gil, K., Kinney, T., \& Spock, A. (1999). Change in the psychological adjustment of children with cystic fibrosis or sickle cell disease and their mothers. Journal of Clinical Psychology in Medical Settings, 6, 373391. doi:10.1023/A:1026219831205

Thompson, R. J., Gustafson, K. E., Hamlett, K., \& Spock, A. (1992). Psychological adjustment of children with cystic fibrosis: The role of child cognitive processes and maternal adjustment. Journal of Pediatric Psychology, 17, 741-755. doi:10.1093/jpepsy/17.6.741 
Timko, C., Baumgartner, M., Moos, R., \& Miller, J. (1993). Parental risk and resistance factors among children with juvenile rheumatic disease: A four-year predictive study. Journal of Behavioral Medicine, 16, 571-588. doi:10.1007/BF00844720

Timko, C., Stovel, K., Moos, R., \& Miller, J. (1992a). A longitudinal study of risk and resistance factors among children with juvenile rheumatic disease. Journal of Clinical Child Psychology, 21, 132-142. doi:10.1207/s15374424jccp2102_5

Timko, C., Stovel, K., \& Moos, R. (1992b). Functioning among mothers and fathers of children with juvenile rheumatic disease: A longitudinal study. Journal of Pediatric Psychology, 17, 705-724. doi:10.1093/jpepsy/17.6.705

Turk, D. (2002). A cognitive-behavioral perspective on treatment of chronic pain patients. In D. C. Turk \& R. J. Gatchel (Eds.), Psychological approaches to pain management: A practitioner's handbook ( $2^{\text {nd }}$ ed., pp. 138-158). New York, NY: Guilford Press.

Vandvik, I. (1990). Mental health and psychosocial functioning in children with recent onset of rheumatic diseases. Journal of Child Psychology and Psychiatry, 31, 961-971. doi:10.1111/j.1469-7610.1990.tb00837.x

Vandvik, I. \& Hoyeraal, H. (1993). Juvenile chronic arthritis: A biobehavioral disease. Some unresolved questions. Clinical and Experimental Rheumatology, 11, 669680. Retrieved from http://www.clinexprheumatol.org/

Varni, J., Wilcox, K., \& Hanson, V. (1988). Mediating effects of family social support on child psychological adjustment in juvenile arthritis. Health Psychology, 7, 421431. doi:10.1037/0278-6133.7.5.421 
Wagner, J., Chaney, J., Hommel, K., Page, M., Mullins, L., White, M., et al. (2003). The influence of parental distress on child depressive symptoms in juvenile rheumatic diseases: The moderating effect of illness intrusiveness. Journal of Pediatric Psychology, 28, 453-462. doi:10.1093/jpepsy/jsg036

Walco, G., Varni, J., \& Ilowite, N. (1992). Cognitive-behavioral pain management in children with juvenile rheumatoid arthritis. Pediatrics, 89, 1975-1077. Retrieved from http://www.pediatrics.org

Wallander, J., \& Varni, J. (1989). Social support and adjustment in chronically ill and handicapped children. American Journal of Community Psychology, 17, 185-201. doi:10.1007/BF00931007

Weinberger, M., Hiner, S., \& Tierney, W. (1986, June). Improving functional status in arthritis: The effect of social support. Paper presented at the meeting of the Arthritis Health Professionals Association, New Orleans.

White, M., Chaney, J., Mullins, L., Wagner, J., Andrews, N., Hommel, K., et al. (2005). Children's perceived illness uncertainty as a moderator in the parent-child distress relation in juvenile rheumatoid diseases. Rehabilitation Psychology, 50, 224-231. doi:10.1037/0090-5550.50.3.224 
Table 1.

Participant Demographics

\begin{tabular}{|c|c|c|}
\hline Variable & $\begin{array}{c}\text { Time } 2 \\
\text { Noncompleters } \\
(N=16)\end{array}$ & $\begin{array}{c}\text { Time } 1 \& 2 \\
\text { Completers } \\
(N=37)\end{array}$ \\
\hline & $\mathrm{N}(\%)$ & $\mathrm{N}(\%)$ \\
\hline \multicolumn{3}{|l|}{ Gender } \\
\hline Female & $4(25)$ & $15(60)$ \\
\hline Male & $12(75)$ & $22(40)$ \\
\hline \multicolumn{3}{|l|}{ Ethnicity } \\
\hline Caucasian & $4(25)$ & $19(51)$ \\
\hline Native American & $4(25)$ & $11(30)$ \\
\hline Biracial & $1(6)$ & $3(8)$ \\
\hline African American & $2(13)$ & $2(5)$ \\
\hline Hispanic & $4(25)$ & $1(3)$ \\
\hline Asian & $1(6)$ & $1(3)$ \\
\hline \multicolumn{3}{|l|}{ Age } \\
\hline 9 & $1(6)$ & $2(5)$ \\
\hline 10 & $2(13)$ & $3(8)$ \\
\hline 11 & $3(19)$ & $1(3)$ \\
\hline 12 & $1(6)$ & $6(16)$ \\
\hline 13 & $0(0)$ & $3(8)$ \\
\hline 14 & $2(13)$ & 7 (19) \\
\hline 15 & $1(6)$ & $5(14)$ \\
\hline 16 & $2(13)$ & $7(19)$ \\
\hline 17 & $4(24)$ & $3(8)$ \\
\hline \multicolumn{3}{|l|}{ Diagnosis } \\
\hline Juvenile rheumatoid arthritis & $9(56)$ & $22(60)$ \\
\hline Systemic lupus erthematosus & $3(19)$ & $9(24)$ \\
\hline Juvenile dermatomyositis & $3(19)$ & $4(11)$ \\
\hline \multirow[t]{2}{*}{ Juvenile ankylosing spondylitis } & $1(6)$ & $2(5)$ \\
\hline & $M(\mathrm{SD})$ & $M(\mathrm{SD})$ \\
\hline Age (years) & $14.05(2.82)$ & $13.7(2.3)$ \\
\hline Illness duration & $2.36(2.4)$ & $2.8(3.4)$ \\
\hline
\end{tabular}


Table 2.

Correlations Between Parent and Child Distress

\begin{tabular}{cccccccccccc}
\hline & $\begin{array}{c}\text { Auto } \\
\text { correlations }\end{array}$ & \multicolumn{4}{c}{$\begin{array}{c}\text { Synchronous } \\
\text { correlations }\end{array}$} & \multicolumn{4}{c}{$\begin{array}{c}\text { Cross-lagged } \\
\text { correlations }\end{array}$} \\
\hline$r \mathrm{C}_{1} \mathrm{C}_{2}$ & $r \mathrm{P}_{1} \mathrm{P}_{2}$ & $z$ & $q$ & $r \mathrm{C}_{1} \mathrm{P}_{1}$ & $r \mathrm{C}_{2} \mathrm{P}_{2}$ & $z$ & $q$ & $r \mathrm{C}_{1} \mathrm{P}_{2}$ & $r \mathrm{P}_{1} \mathrm{C}_{2}$ & $z$ & $q$ \\
\hline .60 & .44 & 1.20 & .22 & .29 & .35 & .33 & .07 & .09 & .45 & $1.98^{*}$ & .40
\end{tabular}

Note. Correlations are partial correlations, with T1 Juvenile Arthritis Functional

Assessment Report - Child controlled. $\mathrm{C}_{1}=$ child distress at Time 1 and $\mathrm{C}_{2}=$ child distress

at Time 2. $\mathrm{P}_{1}=$ parent distress at Time 1 and $\mathrm{P}_{2}=$ parent distress at Time 2. $q=$ measure

of effect size where $.10=$ small, $.30=$ medium, $.50=$ large.

$* p=.02$. 
Figure 1.

Cross-lagged panel design and partial correlations.

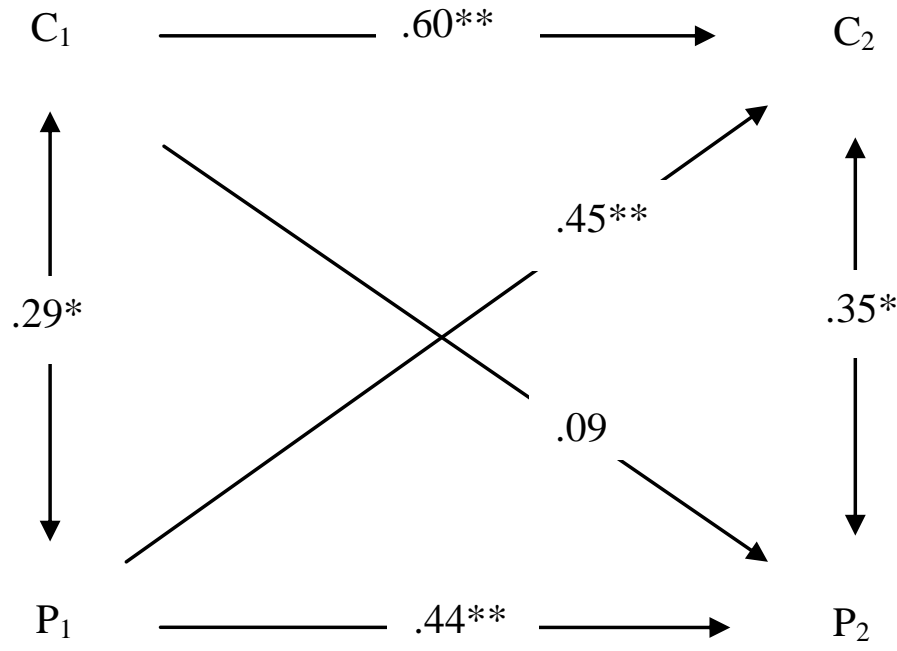

Note. $\mathrm{C}_{1}=$ child distress at Time 1 and $\mathrm{C}_{2}=$ child distress at Time $2 . \mathrm{P}_{1}=$ parent distress at Time 1 and $\mathrm{P}_{2}=$ parent distress at Time 2 .

$* p<.05 . * * p<.01$ 
APPENDIX A 


\section{Background Information Questionnaire}

Hometown:

1. Child's Age:

Parent's Age: Father: Mother:

2. Child's Gender: M $\quad$ F $\quad$ Parent's Gender: $\quad$ M F

3. Child's Ethnicity:

$\begin{array}{cccccc}\text { Caucasian } & \begin{array}{c}\text { African } \\ \text { American }\end{array} & \text { Hispanic } & \begin{array}{c}\text { Native } \\ \text { American }\end{array} & \text { Asian } & \text { Other } \\ 1 & 2 & 3 & 4 & 5 & 6\end{array}$

4. Father's Ethnicity:

$\begin{array}{cccccc}\text { Caucasian } & \begin{array}{c}\text { African } \\ \text { American }\end{array} & \text { Hispanic } & \begin{array}{c}\text { Native } \\ \text { American }\end{array} & \text { Asian } & \text { Other } \\ 1 & 2 & 3 & 4 & 5 & 6\end{array}$

5. Mother's Ethnicity:

$\begin{array}{cccccc}\text { Caucasian } & \begin{array}{c}\text { African } \\ \text { American }\end{array} & \text { Hispanic } & \begin{array}{c}\text { Native } \\ \text { American }\end{array} & \text { Asian } & \text { Other } \\ 1 & 2 & 3 & 4 & 5 & 6\end{array}$

6. Child's current or highest grade completed: 1 Elementary

$2 \quad$ Middle School

3 High School

4 Some college: Years:

7. Marital Status: $1 \quad$ Never married

$\begin{array}{ll}2 & \text { Married } \\ 3 & \text { Divorced } \\ 4 & \text { Cohabitation (living with partner) } \\ 5 & \text { Widowed } \\ 6 & \text { Other: }\end{array}$

8. Parent's highest level of education:

$\begin{array}{lll}\text { Father: } & 1 & \text { Middle School } \\ 2 & \text { High School } \\ 3 & \text { Some College: Years: } \\ 4 & \text { College Degree } \\ 5 & \text { Post-Graduate Degree }\end{array}$




$\begin{array}{lll}\text { Mother: } & 1 & \text { Middle School } \\ & 2 & \text { High School } \\ & 3 & \text { Some College: Years: } \\ 4 & \text { College Degree } \\ & 5 & \text { Post-Graduate Degree }\end{array}$

7. Parent's Occupation: Father: Mother:

8. Living Arrangement:

1 Live alone

2 Live with both parents

3 Live with one parent; Specify parent:

4 Other; Specify:

9. Income: What is the total yearly income of the primary wage earner in your house? (This will be held strictly confidential.)

\begin{tabular}{c}
$0-9,999$ \\
$10,000-19,999$ \\
$20,000-29,999$ \\
$30,000-39,999$ \\
\hline $40,000-49,999$
\end{tabular}

$\begin{array}{r}50,000-59,999 \\ 60,000-69,999 \\ 70,000-79,999 \\ 80,000-89,999 \\ 90,000-99,999 \\ \hline 100,000 \text { or greater }\end{array}$

10. Is your child currently taking any psychoactive medication (e.g., antidepressants, anti-anxiety)?
Yes
No

11. Has your child ever received any type of psychological counseling/therapy?

Yes No

12. Has your child ever received counseling directly related to Juvenile Rheumatic Disease (JRD) (includes juvenile rheumatoid arthritis (JRA), systemic lupus erythematosus (SLE), juvenile spolndylarthropathies, juvenile dermatomyositis (JDMA)

Yes No


APPENDIX B 


\section{Provider Questionnaire}

1. Patient's name:

2. Patient's diagnosis (if multiple diagnoses, please list the rheumatic illness first; please indicate if patient is seropositive or ANA-positive)

3. When was the patient diagnosed with the above rheumatic illness?

Date of diagnosis:

4. What is the patient's current medication regimen?

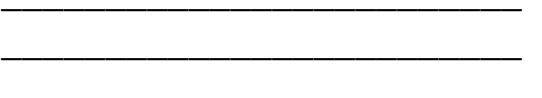

5. Currently, how active is the patient's illness?

$\begin{array}{cccc}1 & 2 & 3 & 4 \\ \text { Clinical Remission } & \text { Clinical Remission } & \text { Inactive } & \text { Active } \\ \text { (off meds 12 mo) } & \text { (on medication) } & \text { Disease } & \text { Disease }\end{array}$

6. Currently, how severe is the patient's illness?

$\begin{array}{ccccc}1 & 2 & 3 & 4 & 5 \\ \text { Inactive } & & \text { Mild } & & \text { Severe }\end{array}$

7. Compared to other patients, how well does this patient adhere to his/her treatment regimen?

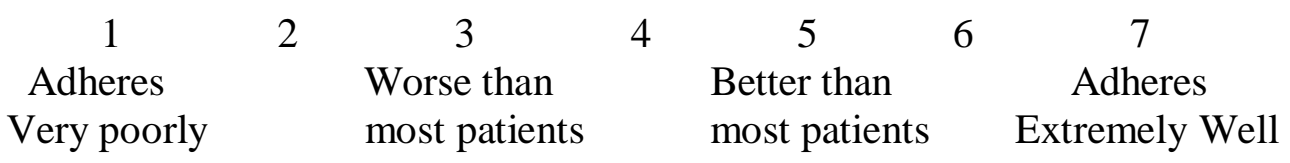

8. Compared to other patients, how well does this patient cope with his/her illness?

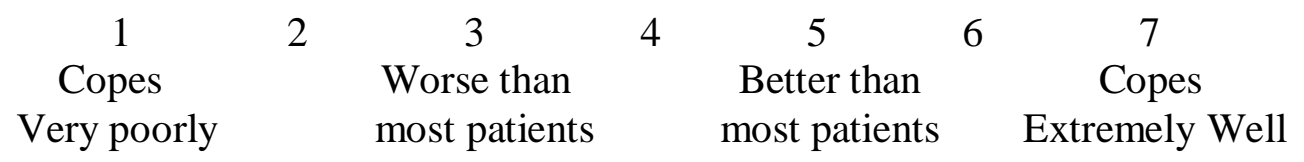


Based on the patient's physical exam, please classify him/her into one of the following four classes:

Class I

Completely able to perform usual activities of daily living (self-care, vocational, and avocational)
Class II

Able to perform usual self-care and vocational activities, but limited in avocational activities
Class III

Able to perform usual self-care activities, but limited in vocational and avocational activities

\section{Class IV}

Limited ability to perform usual self-care, vocational and avocational activities 
APPENDIX C 


\section{Children's Depression Inventory (CDI)}

This form lists feelings and ideas that kids sometimes have. From each group of feelings and ideas, pick one sentence that describes you best for the past two weeks. After you pick a sentence from one group, go on to the next group. There is no right or wrong answer. Just pick the sentence that best describes the way you have been recently. Put a mark like this " $X$ " in the box next to the sentence that you pick.

Here is an example of how this form works. Try it. Put a mark next to the sentence that describes you best.

EXAMPLE: __ I read books all the time

I read books once in a while

I never read books

1. _ I I am sad once in a while

I am sad many times

I am sad all the time

2. _ _ Nothing will work out for me

I am not sure if things will work out for me

Things will work out for me O.K.

3. _ I do most things O.K.

I do many things wrong

I do everything wrong

4. _ I I have fun in many things

I have fun in some things

Nothing is fun at all

5. _ I I am bad all the time

__ I am bad many times

_ I am bad once in a while

6. _ I think about bad things happening to me once in a while I worry that bad things will happen to me

I I am sure that terrible things will happen to me

7. _ I hate myself

I do not like myself

I like myself

8. _ _ _ All bad things are my fault 
- Many bad things are my fault

Bad things are not usually my fault

9.

I do not think about killing myself

I think about killing myself but I would not do it

__ I want to kill myself

10. _ _ I feel like crying every day

I feel like crying many days

I feel like crying once in a while

11. __ Things bother me all the time

Things bother me many times

Things bother me once in a while

12.

I like being with people

I do not like being with people many times

I do not want to be with people at all

13.

I cannot make up my mind about things

It is hard to make up my mind about things

I make up my mind about things easily

14.

I look O.K.

There are some bad things about my looks

I look ugly

15. I I have to push myself all the time to do my school work I have to push myself many times to do my school work Doing school work is not a big problem

16. _ I I have trouble sleeping every night

I have trouble sleeping many nights

I sleep pretty well

17. _ I I am tired once in a while

I am tired many days

I am tired all the time

18.

Most days I do not feel like eating

Many days I do not feel like eating

I eat pretty well

19.

I do not worry about aches and pains

I worry about aches and pains many times

I worry about aches and pains all the time 
20. I do not feel alone I feel alone many times I feel alone all the time

21. I I never have any fun at school I have fun at school only once in a while I have fun at school many times

22. __ I have plenty of friends I have some friends but I wish I had more I do not have any friends

23. _ My school work is all right My school work is not as good as before I do very badly in subject I used to be good in

24. _ I can never be as good as other kids I can be as good as other kids if I want to

_ I I am just as good as other kids

25. _ Nobody really loves me I am not sure if anybody loves me I know somebody loves me

26. I usually do what I am told I do not do what I am told most times I never do what I am told

27. I get along with people I get into fights many times I get into fights all the time

\section{THE END}


APPENDIX D 


\section{Juvenile Arthritis Functional Assessment Report - Children (JAFAR-C)}

Over the past week, how often have you been able to perform each of the activities in the list below?

All the time Sometimes Almost Never

1. Take shirt off hanger

2. Button shirt

3. Pull on sweater over head

4. Turn on water faucet

5. Climb into bathtub

6. Dry back with towel

7. Wash face with cloth

8. Tie shoelaces

9. Pull on socks

10. Brush teeth

11. Stand up from chair not using arms

12. Get into bed

13. Cut food with knife and fork

14. Lift empty glass to mouth

15. Reopen previously opened food jar

16. Walk 50 feet without help

17. Walk up 5 steps

18. Stand up on tiptoes

19. Reach above head

20. Get out of bed

21. Pick up something from floor from standing position

22. Push open door after turning knob

23. Turn head and look over shoulder

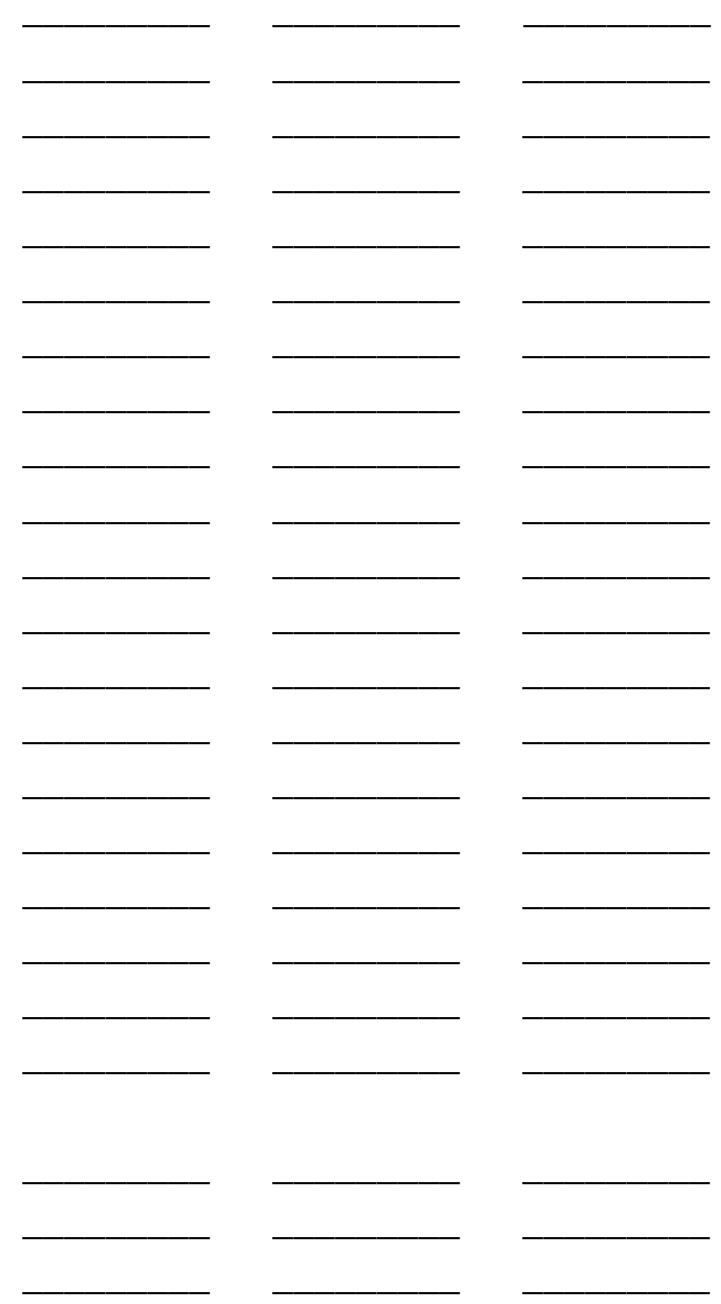


APPENDIX E 


\section{Brief Symptom Inventory (BSI)}

\section{INSTRUCTIONS:}

On the next page is a list of problems people sometimes have. Please read each one carefully, and blacken the circle that best describes HOW MUCH THAT PROBLEM HAS DISTRESSED OR BOTHERED YOU DURING THE PAST 7 DAYS INCLUDING TODAY. Blacken the circle for only one number for each problem and do not skip any items. If you change your mind, erase your first mark carefully. Read the example before beginning, and if you have any questions please ask them now.

\begin{tabular}{|c|c|c|c|c|c|}
\hline 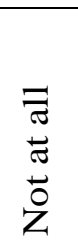 & 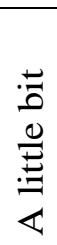 & $\begin{array}{l}\frac{\lambda}{0} \\
\frac{\pi}{\pi} \\
\frac{\overrightarrow{0}}{0} \\
\frac{0}{2}\end{array}$ & 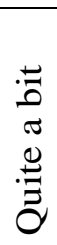 & 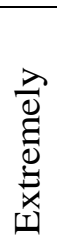 & $\begin{array}{l}\text { Example } \\
\text { How much were you distressed by: }\end{array}$ \\
\hline 0 & 1 & 2 & 3 & $\overline{4}$ & Bodyaches \\
\hline
\end{tabular}




\begin{tabular}{|c|c|c|c|c|c|}
\hline 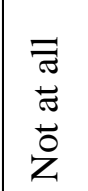 & 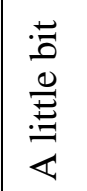 & 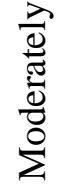 & 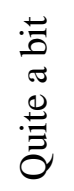 & 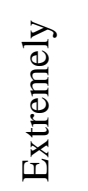 & How much were you distressed by: \\
\hline 0 & 1 & 2 & 3 & 4 & Nervousness or shakiness inside \\
\hline 0 & 1 & 2 & 3 & 4 & Faintness or dizziness \\
\hline 0 & 1 & 2 & 3 & 4 & The idea that someone else can control your thoughts \\
\hline 0 & 1 & 2 & 3 & 4 & Feeling others are to blame for most of your troubles \\
\hline 0 & 1 & 2 & 3 & 4 & Trouble remembering things \\
\hline 0 & 1 & 2 & 3 & 4 & Feelings easily annoyed or irritated \\
\hline 0 & 1 & 2 & 3 & 4 & Pains in heart or chest \\
\hline 0 & 1 & 2 & 3 & 4 & Feeling afraid in open spaces or on the streets \\
\hline 0 & 1 & 2 & 3 & 4 & Thoughts of ending your life \\
\hline 0 & 1 & 2 & 3 & 4 & Feeling that most people cannot be trusted \\
\hline 0 & 1 & 2 & 3 & 4 & Poor appetite \\
\hline 0 & 1 & 2 & 3 & 4 & Suddenly scared for no reason \\
\hline 0 & 1 & 2 & 3 & 4 & Temper outbursts that you could not control \\
\hline 0 & 1 & 2 & 3 & 4 & Feeling lonely even when you are with people \\
\hline 0 & 1 & 2 & 3 & 4 & Feeling blocked in getting things done \\
\hline 0 & 1 & 2 & 3 & 4 & Feeling lonely \\
\hline 0 & 1 & 2 & 3 & 4 & Feeling blue \\
\hline 0 & 1 & 2 & 3 & 4 & Feeling no interest in things \\
\hline 0 & 1 & 2 & 3 & 4 & Feeling fearful \\
\hline 0 & 1 & 2 & 3 & 4 & Your feelings being easily hurt \\
\hline 0 & 1 & 2 & 3 & 4 & Feeling that people are unfriendly or dislike you \\
\hline 0 & 1 & 2 & 3 & 4 & Feeling inferior to others \\
\hline 0 & 1 & 2 & 3 & 4 & Nausea or upset stomach \\
\hline 0 & 1 & 2 & 3 & 4 & Feeling that you are watched or talked about by others \\
\hline 0 & 1 & 2 & 3 & 4 & Trouble falling asleep \\
\hline 0 & 1 & 2 & 3 & 4 & Having to check and double-check what you do \\
\hline 0 & 1 & 2 & 3 & 4 & Difficult making decisions \\
\hline 0 & 1 & 2 & 3 & 4 & Feeling afraid to travel on buses, subways, or trains \\
\hline 0 & 1 & 2 & 3 & 4 & Trouble getting your breath \\
\hline 0 & 1 & 2 & 3 & 4 & Hot or cold spells \\
\hline 0 & 1 & 2 & 3 & 4 & $\begin{array}{l}\text { Having to avoid certain things, places, or activities because } \\
\text { they frighten you }\end{array}$ \\
\hline
\end{tabular}




\begin{tabular}{|c|c|c|c|c|c|}
\hline 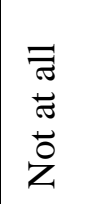 & 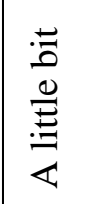 & $\begin{array}{l}\frac{\lambda}{\overrightarrow{0}} \\
\frac{\pi}{\pi} \\
\frac{\overrightarrow{0}}{0} \\
\sum\end{array}$ & $\begin{array}{l}\stackrel{\overrightarrow{0}}{0} \\
\tilde{\sigma} \\
\stackrel{\mathscr{\sigma}}{0} \\
0\end{array}$ & 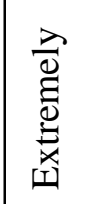 & How much were you distressed by \\
\hline 0 & 1 & 2 & 3 & 4 & Your mind going blank \\
\hline 0 & 1 & 2 & 3 & 4 & Numbness or tingling in parts of your body \\
\hline 0 & 1 & 2 & 3 & 4 & The idea that you should be punished for you sins \\
\hline 0 & 1 & 2 & 3 & 4 & Feeling hopeless about the future \\
\hline 0 & 1 & 2 & 3 & 4 & Trouble concentrating \\
\hline 0 & 1 & 2 & 3 & 4 & Feeling weak in parts of your body \\
\hline 0 & 1 & 2 & 3 & 4 & Feeling tense or keyed up \\
\hline 0 & 1 & 2 & 3 & 4 & Thoughts of death or dying \\
\hline 0 & 1 & 2 & 3 & 4 & Having urges to beat, injure, or harm someone \\
\hline 0 & 1 & 2 & 3 & 4 & Having urges to break or smash things \\
\hline 0 & 1 & 2 & 3 & 4 & Feeling very self-conscious with others \\
\hline 0 & 1 & 2 & 3 & 4 & Feeling uneasy in crowds, such as shopping or at a movie \\
\hline 0 & 1 & 2 & 3 & 4 & Never feeling close to another person \\
\hline 0 & 1 & 2 & 3 & 4 & Spells of terror or panic \\
\hline 0 & 1 & 2 & 3 & 4 & Getting into frequent arguments \\
\hline 0 & 1 & 2 & 3 & 4 & Feeling nervous when you are left alone \\
\hline 0 & 1 & 2 & 3 & 4 & Others not giving you proper credit for your achievements \\
\hline 0 & 1 & 2 & 3 & 4 & Feeling so restless you couldn't sit still \\
\hline 0 & 1 & 2 & 3 & 4 & Feelings of worthlessness \\
\hline 0 & 1 & 2 & 3 & 4 & $\begin{array}{l}\text { Feeling that people will take advantage of you if you let } \\
\text { them }\end{array}$ \\
\hline 0 & 1 & 2 & 3 & 4 & Feelings of guilt \\
\hline 0 & 1 & 2 & 3 & 4 & The idea that something is wrong with your mind \\
\hline
\end{tabular}


APPENDIX F 


\section{Juvenile Arthritis Functional Assessment Report - Parents (JAFAR-P)}

Over the past week, how often has your child been able to perform each of the activities in the list below?

All the time Sometimes Almost Never

1. Take shirt off hanger

2. Button shirt

3. Pull on sweater over head

4. Turn on water faucet

5. Climb into bathtub

6. Dry back with towel

7. Wash face with cloth

8. Tie shoelaces

9. Pull on socks

10. Brush teeth

11. Stand up from chair not using arms

12. Get into bed

13. Cut food with knife and fork

14. Lift empty glass to mouth

15. Reopen previously opened food jar

16. Walk 50 feet without help

17. Walk up 5 steps

18. Stand up on tiptoes

19. Reach above head

20. Get out of bed

21. Pick up something from floor from standing position

22. Push open door after turning knob

23. Turn head and look over shoulder

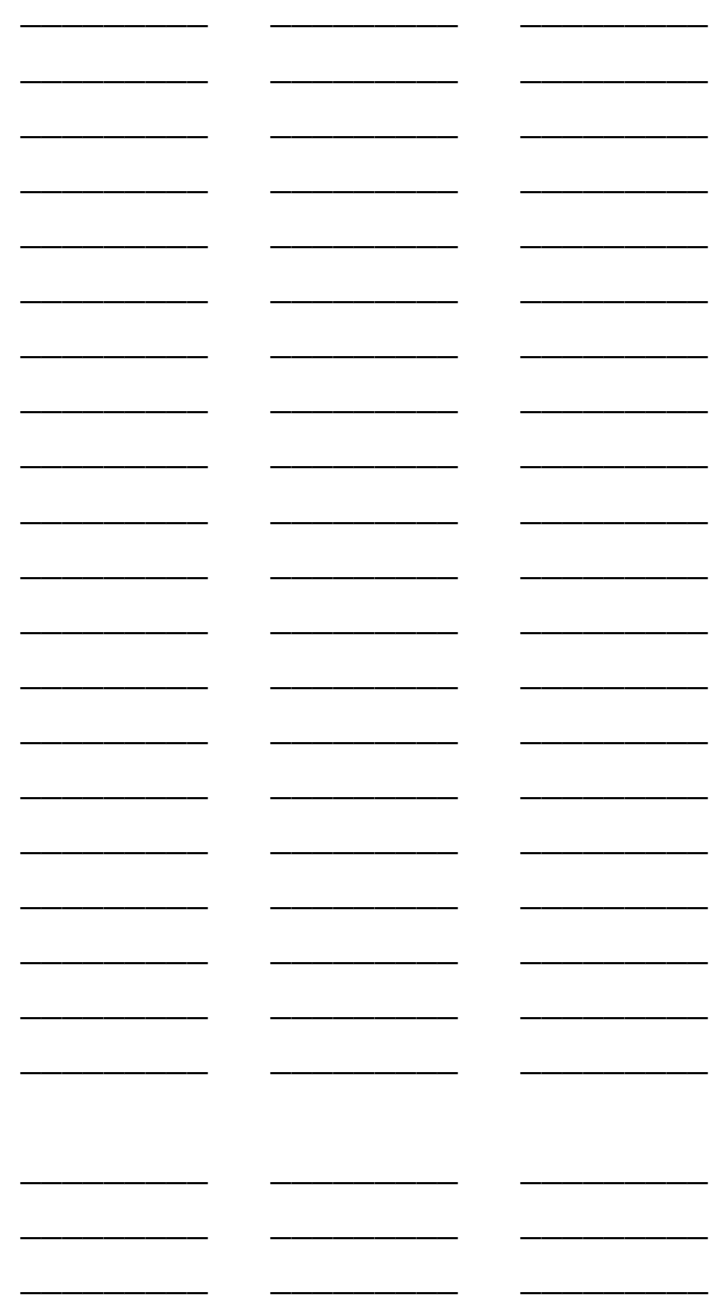


APPENDIX G 
Oklahoma State Univèrsity

Institutional Review Board

Protocol Explres: 2/10/2005

Date: Thursday, February 12, 2004

IRB Application No ASO0104

Proposal THE: PSYCHOLOGICAL COMORBIDTY IN JUVENILE RHEUMATOID DISEASES: A COMPARISONOFAMERTEANINEIANOAND OAUGAGIANS.

Pinncipal
Investigator(s):

Nicole Andrews

215 North Murray

St:llwater, OK 74078

Molly Whito

$407 \mathrm{~N}$. Murray

Stulwater, OK 74078

Janelle Wagner

215 N. Mumay

Strtwater, OK 74078

John M: Chaney

$215 \mathrm{~N}$. Murray

Stillwater, OK 74078

James Jants

OUHSC

OKdahoma City, OK 73104

Roviowed and
Processed as:

Approval Status Pecommended by Reviower(s): Approved

Dear PI :

Your IRB application referenced above has been approved for one calendar year. Please make note of the expiratlon date indicated above. It is the judgment of the reviewers that the rights and welfare of Individuals who may be asked to participate in this study will be respected, and that the research will bo conducted in a manner consistent wth the IRB requirements as outlined in section 45 CFR 46.

As Principal. Investigator, $h$ is your responsibinty to do the following:

1. Conduct this study exactly as it has been apploved. Any modifications to the research protocol must be submitted with the appropriate signatures for IRB approval.

2 Submit a request for continuetion th the study ate lond year. This conthuat must recehv IRB review and apprave calendar

3. Report any adverse events to the IRB Chair promptly. Adverse events are those which are

unantlcipated and Impact the subjects during the course of this research; and

4. Notify the IRB office in writing when your research project is complete.

Please note that approved projects are subject to monitoring by the IRB. If you have questions about the

IRB procedures or need any assistance from the Board, please contact me in 415 Whitehurst (phone:
405-744-5700, colson okstate.edu).

Sincerely.

\section{Cunpolas}

Carol Olson, Chair

Institutional Revlew Board 
VITA

Jamie L. Ryan

Candidate for the Degree of

Master of Science

Thesis: A LONGITUDINAL EXAMINATION OF THE PARENT-CHILD DISTRESS RELATIONSHIP IN CHILDREN WITH JUVENILE RHEUMATIC DISEASE

Major Field: Clinical Psychology

Biographical:

Education:

Completed the requirements for the Master of Science in Clinical Psychology at Oklahoma State University, Stillwater, Oklahoma in July, 2010.

Completed the requirements for the Master of Arts in Clinical Psychology at the University of Northern Iowa, Cedar Falls, Iowa in May, 2008.

Completed the requirements for the Bachelor of Arts in Psychology and Criminal Justice at Mount Mercy College, Cedar Rapids, Iowa in May, 2005.

Experience:

Psychological Services Center, Associate

American Indians Into Psychology, Student Representative

Graduate Psychology Admissions, Student Representative

Graduate Cognitive Assessment, Graduate Teaching Assistant

Abnormal Psychology, Graduate Teaching Assistant/Discussion Leader

Clinical Psychology Advisory Committee, $2^{\text {nd }}$ Year Representative

Psychology Graduate Student Association, Treasurer

Psychology Diversified Students Program, Mentor

Camp Cavett, Voluntary Camp Counselor

Professional Memberships:

American Psychological Association, Division 54

American Psychological Association, Division 37

Association for Psychological Science 
Title of Study: A LONGITUDINAL EXAMINATION OF THE PARENT-CHILD DISTRESS RELATIONSHIP IN CHILDREN WITH JUVENILE RHEUMATIC DISEASE

Major Field: Clinical Psychology

Scope and Method of Study: The objective of the current study was to examine the longitudinal relationships between parent and child distress in a sample of children with juvenile rheumatic diseases (JRDs). A cross-lagged panel correlation analysis tested the temporal precedence of parent distress vs. child distress over a one-year period. Thirtyseven children (ages 9-17; 22 males) diagnosed with JRD and their parents completed self-report measures on two occasions (assessment interval $M=12$ months). Primary outcome measures included the Child Depression Inventory (CDI) and Brief Symptom Inventory (BSI).

Findings and Conclusions: Significant cross-sectional parent-child distress associations were observed at both time points. Moreover, Time 1 parent distress predicted child distress at Time 2 after child-reported functional ability was controlled; Time 1 child distress was unrelated to Time 2 parent distress. Cross-lagged panel correlations demonstrated the temporal precedence of parent distress relative to child distress in the parent-child distress relationship. These preliminary findings underscore the importance of parent distress in parent-child transactional adjustment, and suggest a predominant role for parent distress in children's adjustment to juvenile rheumatic diseases.

ADVISER'S APPROVAL: Larry L. Mullins, Ph.D. 